\title{
O Poder no Executivo: explicações no presidencialismo, parlamentarismo e presidencialismo de coalizão
}

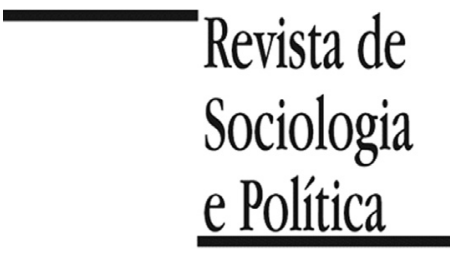

DOI 10.1590/1678-987316245705

\begin{abstract}
Mariana Batista
Resumo

Como a literatura vem analisando o Poder Executivo nos diferentes regimes políticos? A partir da diferença institucional básica entre presidencialismo e parlamentarismo pode-se identificar dois conjuntos de contribuições principais para o entendimento do funcionamento do Executivo em democracias: a literatura sobre a presidência americana e as discussões sobre os governos de coalizão no parlamentarismo europeu. O que os dois conjuntos de teorias têm em comum é a preocupação com a política intra-executivo. Esta literatura é analisada, identificando as principais questões, instituições, comportamentos e variáveis enfatizadas. Como resultado tem-se a sistematização e comparação dos principais argumentos sobre o funcionamento interno do Executivo não só no presidencialismo e no parlamentarismo, mas também a contribuição para a explicação do caso específico do presidencialismo de coalizão.
\end{abstract}

PALAVRAS-CHAVE: Poder Executivo; presidencialismo; parlamentarismo; presidencialismo de coalizão; gabinete.

Recebido em 21 de Maio de 2014. Aceito em 2 de Novembro de 2014.

\section{Introdução ${ }^{1}$}

\author{
1 Agradeço a Marcus Melo \\ pelo apoio, Magna Inácio pelo \\ constante incentivo e Gabriela \\ Tarouco pelos inúmeros \\ comentários. Agradeço ainda \\ aos pareceristas anônimos da \\ Revista de Sociologia e \\ Política pelas excelentes \\ sugestões. Quaisquer \\ incorreções remanescentes são \\ de minha total \\ responsabilidade.
}

$\mathrm{O}$ papel do Poder Executivo nos sistemas políticos democráticos, especialmente sua força e interação com o Poder Legislativo, é um tema central na literatura institucional. Questões como a separação dos poderes, a força do Executivo frente ao Legislativo e sua capacidade de governo se tornaram recorrentes. Nota-se que os poderes e atuação do Executivo frente ao Legislativo variam expressivamente em sistemas presidencialistas e parlamentaristas. O objetivo deste ensaio é deslocar o foco da atuação e desempenho externo do Executivo na sua relação com o Legislativo para a política intraexecutiva, isto é, o funcionamento interno das estruturas de poder no Executivo nos diferentes tipos de regime.

A principal diferença entre presidencialismo e parlamentarismo está na separação de origem e de sobrevivência entre os poderes Executivo e Legislativo (Stepan 1990). No parlamentarismo, o governo somente existe enquanto mantém apoio da maioria do Legislativo e o foco do poder está no gabinete. Quando nenhum partido alcança status majoritário o governo é formado com apoio de uma coalizão multipartidária. Esse é o caso de grande parte das democracias europeias. No caso do presidencialismo, o foco está no presidente e este é eleito por voto direto e normalmente possui autonomia para decidir a composição do governo. Sua estabilidade tem por base o mandato e não depende de apoio legislativo. O caso mais influente de presidencialismo é o sistema americano. O sistema político brasileiro é atualmente definido como um presidencialismo de coalizão (Abranches 1988). Esse sistema tem por base um presidente eleito diretamente e com mandato próprio, mas que para governar conta com o apoio de uma coalizão multipartidária. 
${ }^{2}$ Resenha anterior sobre os estudos sobre o Executivo de forma mais ampla pode ser encontrada em Figueiredo (2004).
Como a literatura vem analisando o papel dos atores, instituições e o processo decisório do Poder Executivo nesses diferentes regimes? O objetivo deste trabalho é resgatar, de forma sistemática, as principais contribuições da literatura sobre a dinâmica e funcionamento interno do Poder Executivo no presidencialismo, no parlamentarismo e no caso do presidencialismo de coalizão $^{2}$. Para tanto, a estratégia é focar os casos com maior acúmulo teórico. No caso do presidencialismo, as principais análises têm por objeto ou se inspiraram no presidencialismo americano. No caso do parlamentarismo o foco está nos governos de coalizão da Europa ocidental. Argumentos sobre o presidencialismo de coalizão aparecem de forma mais dispersa em contribuições pontuais na América Latina.

Este ensaio está organizado da seguinte forma: primeiramente, a literatura sobre o presidencialismo é analisada. Nota-se aqui a subdivisão da literatura em dois enfoques específicos, o enfoque personalista, que trata principalmente da figura do presidente, e o enfoque institucional, que analisa o desenho institucional do Executivo. Em seguida é analisada a literatura sobre os governos de coalizão no parlamentarismo, que se subdividem em estudos sobre a formação do governo e nos estudos sobre governança. Por último, analisa-se a literatura incipiente sobre o presidencialismo de coalizão.

\section{A presidência norte-americana: entre a personalidade e a institucionalização}

As análises sobre o papel do presidente e da presidência se constituem num dos tópicos mais difundidos da Ciência Política americana (King 1993). Contudo, mesmo constatando a grande difusão de estudos sobre o Poder Executivo, regularidades empíricas e o acúmulo teórico demoraram a aparecer. Por muito tempo os avanços observados em áreas similares como os estudos legislativos, comportamento eleitoral ou até nas relações Executivo-Legislativo não foram sentidos na área de estudos presidenciais e no estudo específico da dinâmica intra-executivo, denotando uma lógica particular de construção do campo (Moe 1993).

Dentro dessa lógica de construção do campo podem ser observadas duas correntes principais: o foco na personalidade ou na liderança pessoal do presidente e as análises da presidência institucional. O elemento inicial do debate está na seguinte questão: dado que no sistema presidencialista o presidente é o chefe absoluto do Poder Executivo, a personalidade e o estilo individual dos presidentes determinam os resultados ou as regras e procedimentos da instituição constrangem e orientam os comportamentos gerando regularidades? Os trabalhos sobre a presidência americana podem ser classificados de acordo com a resposta que dão a essa questão.

\section{II.1. A abordagem legal e o domínio da personalização nos estudos sobre a presidência}

É interessante notar que, inserindo-se na orientação mais geral da Ciência Política daquele momento histórico, as primeiras análises do Executivo americano podem ser classificadas como institucionais, ainda que um institucionalismo antigo e legalista (idem). Classificada originalmente como a abordagem legal da presidência (Edwards III 1985), esse tipo de análise tem por foco os poderes formais e a autoridade constitucional do cargo de presidente. "Os pesquisadores, nesta perspectiva, analisam a Constituição, as leis, os tratados e os precedentes legais com o objetivo de entender as fontes, o escopo e o uso dos poderes formais do presidente, incluindo as suas limitações legais" (idem, p.46).

Dado que o principal objetivo dessa perspectiva é avaliar os presidentes de acordo com o seu poder formal, identificando a força e também as limitações do 
cargo, grande parte dos resultados podem ser classificados como descritivos e de orientação histórica. O foco da abordagem está na descrição dos poderes formais e a sua evolução ao longo do tempo, uma vez ou outra com ênfase em mecanismos específicos como a intervenção do presidente na liberação de verbas, o poder de emitir ordens executivas e o poder de veto.

Frequentemente, o estudo dos poderes do presidente leva não só a análises da realidade do cargo, mas também a avaliações normativas de qual deveria ser a extensão e o escopo dos poderes do presidente, considerando-se o equilíbrio da separação de poderes no sistema político americano.

As críticas que podem ser levantadas a essa abordagem é que claramente poder formal não se traduz em poder de fato e também que grande parte do que um presidente faz para governar não está previsto na letra da Constituição. Nas palavras de Edwards III: "A maior parte do relacionamento do presidente com o público, o Congresso, a assessoria da Casa Branca e a burocracia do Estado não se encaixa facilmente no âmbito da perspectiva legal" (idem, p.47).

Para além da clara limitação da perspectiva legal em abarcar a totalidade do escopo de atuação do presidente, a principal crítica é de cunho metodológico. A abordagem legal não se presta à explicação. Apesar do grande número de trabalhos avaliando se os poderes do presidente são apropriados, não há estudos que identifiquem o poder de tais regras formais em orientar os comportamentos, por que alguns comportamentos ocorrem dentro dos limites formais, por que tantos outros escapam da regra e quais são as consequências desses fatos.

A revolução comportamentalista na Ciência Política teve por principal efeito deixar o argumento institucional-legal em segundo plano e enfatizar aquilo que de fato poderia ser observado: o comportamento. Como não poderia ser diferente, o comportamentalismo influenciou diretamente os estudos sobre a presidência americana, deslocando o foco dos poderes formais do presidente para as características pessoais de liderança (Moe 1993).

Em trabalho clássico, Neustadt (1960) estabelece o foco dos estudos presidenciais no poder pessoal do presidente, na sua capacidade de liderança e no seu poder de persuadir os demais atores a agirem de acordo com os seus interesses. De acordo com o argumento de Neustadt, poderes formais não garantem ação e estar no topo da hierarquia formal não o estabelece no topo do sistema político de fato.

Uma vez investido no cargo, o problema do presidente passa a ser identificar estratégias de fazer o seu governo trabalhar em função dos seus interesses. A ideia é a de que o sistema de divisão de poderes nos Estados Unidos gera um presidente que tem que buscar transformar uma suposta autoridade formal em poder de fato. As variáveis relevantes passam longe das instituições e focam a capacidade de persuadir, de convencer, de barganhar acordos políticos e convencer os atores políticos de que seus interesses são os mesmos que os do presidente (Howell 2003). Explicar o desempenho da presidência não tem por base a presidência como organização, poderes legais ou procedimentos: "my theme is personal power and its politics: what it is, how to get it, how to keep it, how to use it. My interest is in what a president can do to make his own will felt in his own administratition" (Neustadt 1960, p.vii) e "Presidential power is the power to persuade" (idem, p.10).

A necessidade de buscar influência vai além dos atores externos ao Poder Executivo. O poder da barganha é o que faz o presidente alcançar seus objetivos no Congresso, no Judiciário e entre os entes subnacionais, mas também é fundamental para a liderança dentro da estrutura do próprio Executivo. Para o argumento, mesmo existindo a visão externa de uma estrutura única, "o" Poder Executivo, no qual o presidente tem autoridade absoluta, quando o presidente 
precisa de algo feito por seu gabinete, suas agências administrativas, o Exército ou até mesmo de sua assessoria direta, seu poder de persuasão é necessário e apresenta as mesmas limitações vistas nas negociações com atores externos.

A qualidade do governo é totalmente dependente das qualidades pessoais do seu chefe. De acordo com as descrições de Neustadt (idem), o estilo de Roosevelt era o modelo a ser seguido e o exemplo negativo de liderança a presidência de Eisenhower. O primeiro se caracteriza por uma gestão informal, altamente personalizada e focada no presidente, com controle direto sobre o processo decisório de modo que o próprio presidente tinha máximo envolvimento e controle. Já Eisenhower construiu uma presidência com organizações formais e um modelo não político de liderança burocrática e hierarquizada onde cada peça tem o seu papel, culminando na decisão presidencial (Neustadt 1960; Moe 1993).

Esse argumento da liderança presidencial tornou-se dominante no debate e ainda hoje muitos autores discutem a personalidade presidencial e estilos de liderança (Hargrove 1993). Contudo, críticas contundentes podem ser apontadas. Moe (1993) aponta que a dominância do argumento da liderança presidencial não corresponde às mudanças observadas na realidade. Enquanto Neustadt (1960) exaltava o modelo da liderança e controle pessoal de todas as decisões pelo presidente, a presidência americana passava por um processo de aumento, institucionalização e mudança organizacional.

A descrição atual da presidência tem por base centenas de funcionários, com papeis definidos e redes organizacionais altamente diferenciadas, ganhando estabilidade e uniformidade ao longo do tempo. Não é esperado do presidente moderno que controle a totalidade das decisões sobre programas legislativos, regulações e dotações orçamentárias, que negocie diretamente com cada parlamentar a aprovação de cada projeto de lei, etc. Há divisão do trabalho e especialização de modo a alcançar essa infinidade de decisões que são estabelecidas pelo Poder Executivo. Resumindo, "at precisely the same time that Neustadt's work was reorienting scholarly thinking around the concept of the personal presidency, the presidency itself was becoming highly institutionlized" (Moe 1993, p.340).

Outra crítica é de cunho metodológico: o foco se deslocou do formal para o informal, do estrutural para o pessoal buscando sempre explicar a totalidade do fenômeno sob análise. A unidade de análise normalmente é o presidente, orientando os trabalhos para estudos de caso com base em evidência histórica e descritiva das presidências específicas. Os trabalhos sobre a presidência não seriam propriamente teóricos, tendo em vista que a "metodologia do personalismo" levava a explicações baseadas em anedotas, história, descrição, fragmentos impressionistas e julgamentos informados (Edwards III 1985). Nas palavras de um dos maiores expoentes do debate:

"Good work remained, above all else, a matter of good writing - writing so elegant, so interwoven with stories and illustrations, a flush with historical details, that one might almost overlook its absence of theory, testing, logical rigor, objectivity, or other mainstays of modern social science" (Moe 1993, p.344).

De acordo com King (1993), os estudos sobre a presidência são o último bastião de pesquisa histórica e não quantitativa da Ciência Politica americana e muito disso se deve a um entendimento equivocado dos pesquisadores de que buscar o conhecimento sistemático é sinônimo de analisar aspectos irrelevantes da presidência. Segundo o autor, "although probably more has been written about the presidency than all other areas of American politics combined, most work in the field is not to the point where concepts are to be measured and theories tested systematically" (idem, p.387). 


\section{II.2. A abordagem institucional}

3 Esse é um tema de pesquisa clássico na Ciência Política americana: o principal varia, podendo ser o presidente, $o$ Congresso ou ambos.
A sugestão de Moe (1993) para superar essas limitações do campo é focar o aspecto institucional da presidência, especificamente os tópicos da centralização, politização e os modelos de escolha estrutural das agências administrativas. De acordo com o autor:

"Presidential scholars must take a more restrictive view of what they want to explain. They cannot explain everything about the presidency that they find interesting or importante. They can explain institutional aspects better than they can explain personal aspects, and they can probably explain some properties of institutions - structure, in particular - more readily than others. In the long run, it seems to me that they will learn more about the presidency, produce better theories, and invest their scarce resources more wisely if they concentrate their scientific efforts more narrowly and strategically" (idem, p.354).

Moe (idem) argumenta que uma teoria institucional da presidência construída com base na teoria da escolha racional é fundamental pois insere as explicações sobre a presidência nas explicações mais gerais sobre o sistema político como um todo, abrindo caminho para uma explicação unificada da política. A aplicação desse princípio pode ser vista em alguns dos seus trabalhos.

As fundações para o desenvolvimento desse argumento estão no estudo das relações intra-executivo, focando o controle do presidente sobre as agências administrativas (Moe 1982). O presidente delega poderes para agências autônomas, que podem trabalhar contra os seus interesses. As análise são feitas com base no modelo principal-agent e buscam identificar se o presidente é capaz de manter a agência sob controle, trazendo resultados favoráveis às preferências do seu principal $^{3}$. Focando a ideologia do presidente, os trabalhos buscam identificar se esse ator é capaz de controlar os resultados da agência (Moe 1982; Wood 1988; Wood \& Waterman 1991).

No seu bastante influente trabalho sobre a presidência politizada, Moe (1985) propõe uma abordagem do Executivo a partir do foco na relação entre a presidência e a burocracia em geral do Executivo. A teoria propõe que com o aumento e a maior complexidade das questões a serem tratadas pelo presidente e a observada maior fragmentação da burocracia, o presidente buscará trazer para sua órbita de decisão o maior número de funções, de forma a fazer valer as suas preferências. Isso porque o custo de agência passa a aumentar e o presidente "centraliza" para que as políticas que são construídas no Executivo de fato reflitam as suas preferências.

Para esta literatura, centralizar significa deslocar funções da burocracia mais ampla do Executivo para o presidente e, particularmente no caso americano, para o Executive Office of the President. Nesse sentido, há uma divisão entre os ministérios e agências independentes de um lado e o presidente e seus órgãos de assistência direta do outro. Ainda de acordo com Moe (idem), uma estratégia adicional para impor suas preferências às políticas é a chamada "politização", que tem por objetivo aparelhar a burocracia e agências independentes com funcionários de sua confiança.

Apesar de bastante influente para a abordagem institucional da presidência, o argumento de Moe (idem) acerca da centralização e da politização não trazia a especificação necessária para o seu efetivo teste empírico. Isto é:

"The theory that Moe postulated, however, lacked the dynamic components needed to identify when, pricisely, presidents would centralize or politicize authority and when they would not - that is, Moe's work did not generate any clear comparative statics. Moreover, Moe's empirical analysis resembled the existing literature at the time. Evidence of centralization and politicization consisted of 
selected case studies of individual agencies and a handful of policies that helped write, and little else" (Howell 2006, pp.308-309).

O teste empírico das hipóteses estabelecidas no trabalho de Moe (1985) é realizado por Rudalevige (2002). Rudalevige analisa a escolha entre a produção centralizada das iniciativas legislativas no presidente ou a delegação para os ministérios. Em outras palavras, o presidente tem um problema do tipo "make or buy" com a escolha sobre formular a política dentro da presidência ou delegá-la à burocracia. Há custos de transação associados às duas opções e o presidente tem de escolher entre duas diferentes estruturas de governança. Sob quais circunstâncias o presidente vai escolher um governo centralizado sobre a delegação à burocracia? Segundo o autor:

"The cost of policy formulation to the president, then is a similar combination of price and a consideration of reliability. The latter hinges on whether the president trusts the information he is given, with trust, in turn, seen as an assessment of the expertise of the giver, weighted by the degree to which she shares presidential preferences. [...] Clearly the calculation of presidential transaction costs will not translate into dollars and cents or, for that matter, into any exact unit of measurement. We can instead aim to define shift parameters - to get a sense of which options are more costly than others under what circumstances, and thus to make predictions about effects, in direction and intensity, of different management environments on president's choices regarding centralization and policy formulation" (idem, pp.31-32).

O autor propõe que maior centralização é esperada quando: (i) a proposta envolve projetos com vários setores ou reorganização do governo, já que as informações fornecidas pelos ministérios e pela burocracia mais ampla do governo em tais casos não são confiáveis; (ii) o presidente tem forte apoio direto de uma burocracia institucionalizada, de modo que o custo da informação diminui e é mais confiável; (iii) a proposta requer urgência, uma vez que a espera de uma resposta da burocracia não é viável; (iv) a proposta refere-se a um tema completamente novo e (v) não há burocracia especializada dentro do quadro mais amplo do Executivo. Em contraste, mais delegação é esperada quando: (i) a complexidade da política aumenta e conhecimento especializado é necessário; (ii) quando a maioria no Congresso é ideologicamente próxima do presidente, dado que o Legislativo é também um principal para a burocracia (idem).

Esse argumento ficou conhecido como o da centralização contingente e se mostra bastante inovador por tratar os dilemas de delegação e controle na formulação da agenda legislativa dentro do próprio Poder Executivo. Como um desenvolvimento dessa abordagem, Rudalevige e Lewis (2005) testam o argumento de Moe (1985) na sua total extensão, analisando o uso da estratégia de centralização e de politização da burocracia simultaneamente. Os autores desenvolvem o argumento de que centralização e politização na verdade são estratégias substitutas e não complementares, como poderia ser entendido no argumento original de Moe (idem), dados os custos associados a cada forma de intervenção. Finalmente, ainda dialogando com Moe (idem), Lewis (2009) faz um alerta para a aceitação direta da premissa de que a politização é um mecanismo de controle político da burocracia. Segundo o autor, a politização pode ser orientada por objetivos de distribuição de patronagem para os aliados políticos e não com o objetivo de controle político. Sendo esse controle muitas vezes diminuído com a indicação política.

Para além desse foco na formulação da agenda legislativa, alguns trabalhos deslocaram o olhar para a atuação não legislativa do Executivo. Isso porque o presidente americano é reconhecidamente fraco nesse aspecto, uma vez que não tem o poder constitucional de iniciar legislação. Nesse sentido, muitos trabalhos 
buscam identificar a atuação do presidente de acordo com aquilo que esse ator tem poder para fazer independentemente da concordância de outros atores.

Presidentes têm trabalhado com base em sua autoridade administrativa e formulado políticas unilateralmente sem interferência do Congresso ou do Judiciário (Mayer 2001). O mecanismo mais utilizado para a ação unilateral são as executive orders, diretivas presidenciais que requerem ou autorizam uma ação no Poder Executivo, instrumentos legais que criam ou modificam leis, procedimentos ou políticas por decreto (idem).

Esse mecanismo é constantemente utilizado para criar ou abolir agências administrativas, determinar como leis serão implementadas, entre outras ações dentro do limite constitucional de ação do Executivo. Com base na análise desses atos unilaterais do presidente, quando este busca agir sem a anuência do Congresso, observa-se um descompasso entre o aumento contínuo do uso da ação unilateral pelos presidentes americanos e a ausência de análises sistemáticas sobre o uso desse mecanismo. Mesmo aparentando ser usado apenas para ações cotidianas e sem impactos profundos na política americana, Howell identifica que "many of the most important policy changes in the modern era came at the hands of presidents going it alone" (Howell 2003, p.xiii).

As ordens executivas se tornaram uma forma de o presidente governar com o "golpe da caneta" (Mayer 2001). Contudo, não é uma ação sem custos. A ação unilateral é vista como um caminho para a ditadura presidencial e a negação do poder do Congresso. A crítica mais branda atesta o déficit de accountability associado com o uso desse mecanismo. Dessa forma, a questão que se torna premente é sob quais condições o presidente fará valer o seu poder de agir unilateralmente.

O modelo de política unilateral de Howell (2003) estabelece como diferentes contextos institucionais afetam as oportunidades e incentivos para o presidente agir unilateralmente. As principais predições do modelo são que governos unificados, a baixa capacidade institucional do Congresso e quando um novo governo é estabelecido (ao invés de um governo reeleito) são fatores que incentivam a ação unilateral.

O presidencialismo americano tem características institucionais específicas e um conjunto de argumentos foi construído para tentar explicar o funcionamento do Poder Executivo sob a regra de separação dos poderes. Os fundamentos legalistas e desprovidos de política foram substituídos por um argumento focado na liderança e no estilo pessoal do presidente. Com o desenvolvimento contínuo, foi observada a crítica ao argumento focado na pessoa do presidente e cada vez mais enfatizada a importância das instituições e como estas afetam o cálculo dos atores, até mesmo dentro do Poder Executivo.

A teoria da escolha racional e o neoinstitucionalismo, que se tornaram dominantes nos estudos legislativos e na explicação do comportamento eleitoral, finalmente passaram a ter espaço também na explicação da ação presidencial. A presidência é regida por regras e procedimentos, o Executivo é um conjunto de organizações e atores que realizam cálculos racionais.

Considerar esses aspectos do Poder Executivo não significa excluir o principal aspecto institucional do presidencialismo: o presidente é o chefe absoluto do governo. A questão passa a ser compreender as escolhas que esse ator faz sob o constrangimento das instituições tendo em vista os seus objetivos. Dessa forma, contribuições foram feitas no sentido de compreender quando o presidente centralizará o processo de formulação de sua agenda legislativa e quando delegará para os membros do seu gabinete, quando usará o mecanismo da ação unilateral e quando recorrerá ao processo legislativo usual. A próxima seção 
desloca o foco para a estrutura institucional do parlamentarismo, identificando as principais contribuições na explicação do Poder Executivo.

\section{Governos de coalizão no parlamentarismo europeu}

No parlamentarismo, quando um determinado partido alcança a maioria legislativa, este forma o governo e se mantém no poder enquanto contar com o apoio majoritário. Contudo, quando nenhum partido alcança a maioria legislativa, e essa é atualmente a situação mais frequente nos sistemas parlamentaristas europeus (Strom, Muller \& Bergman 2008), como o governo será formado? Quem comporá o ramo executivo do poder? Até quando o governo se mantém no poder? Como as decisões serão tomadas? A resposta para essas questões se tornou um dos principais programas de pesquisa da Ciência Politica contemporânea, focando os governos de coalizão como solução para a formação de governos em sistemas parlamentaristas.

Os estudos sobre as coalizões no parlamentarismo europeu podem ser divididos em duas vertentes principais: os estudos sobre formação e os estudos sobre governança. Os estudos sobre formação se preocupam com questões como quantos e quais partidos farão parte da coalizão, qual o tamanho e disposição ideológica e qual o papel do formateur. Já os estudos sobre governança se preocupam com o que acontece depois que o governo é formado. Isto é, como as coalizões de fato governam. O foco está no processo decisório e em quais atores influenciam as decisões e como (Martin \& Vanberg 2011).

\section{III.1. Modelos de formação: tamanho, ideologia e instituições}

O trabalho pioneiro que estabeleceu o ritmo inicial dos estudos sobre a formação de governos de coalizão é o de Riker (1962) sobre o tamanho das coalizões. Referindo-se a coalizões como um grupo composto de ao menos dois atores que buscam a tomada de decisão, do qual as coalizões governativas são um tipo específico, Riker põe em discussão a aplicação do argumento de Downs (1999 [1957]) ao estudo das coalizões.

Em uma das passagens mais importantes da teoria política positiva, Downs (idem) afirma que "os governos democráticos agem racionalmente para maximizar o apoio político" (idem, p.41). Assim como as firmas e os consumidores no mercado, governantes e eleitores também agem racionalmente e dessa forma é possível prever os resultados políticos em equilíbrio.

Riker (1962) toma por base o pressuposto da racionalidade downsiano, mas apresenta uma incoerência no argumento quando aplicado ao estudo das coalizões. De acordo com o argumento de Downs (1999) é esperado que as coalizões maximizem votos, como exposto na passagem acima. Contudo, para Riker (1962) os atores políticos não buscam a maximização de votos, mas sim o número suficiente de votos para vencer. Esse é o argumento das coalizões minimamente vencedoras (minimum winning coalitions).

$\mathrm{O}$ argumento das coalizões minimamente vencedoras é primeiramente apresentado no livro fundador da teoria dos jogos de Von Neumann e Morgenstern (1944), mas traduzido num modelo formal por Riker (1962), que o estabelece como "the size principle": "In n-person, zero-sum games, where side-payments are permitted, where players are rational, and where they have perfect information, only minimum winning coalitions occur" (idem, p.32).

O princípio apresentado acima estabelece que os atores, aqui identificados como os partidos, apenas formem coalizões do tamanho suficiente para ganhar, não incluindo membros "supérfluos". A explicação tem por base a racionalidade dos atores: o governo é identificado como uma espécie de prêmio a ser 
dividido entre os ganhadores, de forma que quanto maior o número de ganhadores, menor a participação de cada ganhador na divisão do prêmio. Nas palavras de Riker, "the greater the number of losers, the greater the sum of their losses, and hence the gains of the winners. Or conversely, the fewer the winners, the more each can expect to win" (idem, p.33).

Dessa forma, o argumento contradiz o postulado da maximização estabelecendo que a forma racional de dividir os ganhos do poder (controlar o governo) é através da formação de coalizões que não contenham membros desnecessários para vencer e assim cada membro da coalizão receberá a maior parcela possível dos ganhos. Como os atores são racionais e possuem informação perfeita, eles sabem que a forma de maximizar os ganhos é através de coalizões mínimas, o que faz com que esse tipo de coalizão seja formada. A crítica ao axioma dowsiano é assim resumida:

"Downs assumed that political parties (a kind of coalition) seek to maximize votes (membership). As against this, I shall attempt to show that they seek to maximize only up to the point of subjective certainity of winning. After that point they seek to minimize, that is, to maintain themselves at the size (as subjectively estimated) of minimum winning coalition" (ibidem).

Desenvolvida simultaneamente ao argumento formal de Riker (1962) está a constatação sociológica estabelecida por Gamson (1961), também com base no argumento geral de Von Neumann e Morgenstern (1944) das coalizões minimamente vencedoras, estabelecendo o que ficou conhecido como o princípio da proporcionalidade ou Lei de Gamson.

Algumas definições são importantes. Gamson (1961) define uma coalizão como o uso conjunto de recursos por duas ou mais unidades sociais para chegar a uma decisão, no caso aqui considerado conquistar o poder de decidir. "Power is the currency of politics" (idem, p.374). Para a decisão ser tomada é preciso uma quantidade crítica de recursos associados aos participantes e há um payoff estabelecido como recompensa.

No caso aqui de interesse, a decisão em questão é a formação do governo, os participantes são os partidos políticos, os recursos a quantidade de cadeiras controladas ou o peso do partido e o payoff a parcela de poder controlada no governo identificada como os ministérios no gabinete. Resta saber qual a regra que rege a distribuição desses benefícios. Esta é a lei de Gamson: "Any participant will expect others to demand from a coalition a share of the payoff proportional to the amount of resources which each contribute to a coalition" (idem, p.376). As condições para a lei de Gamson se sustentar são as seguintes:

" 1 . There is a decision to be made and there are more than two social units attempting to maximize their share of the payoffs. 2. No single alternative will maximize the payof to all participants. 3. No participant has dictatorial powers, i.e., no one has initial resources sufficient to control the decision by himself. 4 . No participant has veto power, i.e., no member must be included in every winning coalition" (idem, p.374).

O payoff total é constante e o ator tem que escolher entre opções de coalizão que maximize a sua participação no payoff. Nesse caso, é esperado que os participantes demandem participação no payoff proporcional aos recursos controlados para a tomada de decisão. É interessante notar que para essa conclusão se sustentar o participante precisa ter alternativas, quando a condição quatro acima é mantida, já que "where one member has veto power, there is no alternative to his inclusion; he could no longer be expected to demand only a proportional share of the payoff" (Gamson 1961, p. 377).

A Lei de Gamson não se trata de um modelo formal, mas sim de uma formulação para teste empírico. Tais testes foram feitos com base na proporção 
de cadeiras controladas pelo partido e a proporção de ministérios recebidos no governo como indicadores, respectivamente, de recursos do partido e payoff na divisão do governo, e vêm sendo replicados praticamente em todos os trabalhos sobre formação de governos de coalizão, até mesmo fora do parlamentarismo europeu. Os resultados indicam uma das associações mais expressivas da Ciência Política. Nas palavras de Laver (1998, p.4) "one of the highest nontrivial $r$-squared figures in political science $(0.93)$ ”.

Até o momento, os modelos de formação de governo orientados pelo princípio do tamanho e o argumento da demanda proporcional de participação no governo estabelecem implicitamente o que é conhecido como o argumento office-seeking dos partidos. Isto é, o prêmio a ser dividido são posições no gabinete e isso é tudo a ser considerado no jogo de formação da coalizão. Alguns trabalhos posteriores passaram a enfatizar a dimensão ideológica na formação de governos de coalizão. Isto é, algumas coalizões são mais prováveis do que outras e isso acontece devido a razões de proximidade ideológica entre os futuros parceiros. Aqui a ênfase é na busca por cargos, porém, esses cargos seriam um instrumento para a implementação de políticas. Como após a formação da coalizão é esperado que os membros governem juntos, considerações acerca da policy-position dos atores são de importância.

O modelo de Axelrod (1970) é um dos primeiros a considerar o papel da ideologia na formação do governo. Seu postulado prevê a formação de coalizões mínimas conectadas vencedoras (minimal connected winning coalitions). As coalizões seriam conectadas ideologicamente no sentido de que somente partidos adjacentes no espectro ideológico seriam parceiros em coalizões viáveis dentre as opções de coalizões minimamente vencedoras. Sob orientação do argumento de Downs (1999) de que a competição partidária se dá no eixo esquerda-direita, os partidos seriam dispostos nesse eixo e somente coalizões conectadas se formariam, como por exemplo coalizões entre partidos de esquerda ou partidos de direta, mas não entre partidos dos polos opostos do espectro (Axelrod 1970).

Um aspecto característico do argumento de Axelrod (idem) é o de que somente o caráter ordinal do posicionamento ideológico é levado em consideração. De Swaan (1973) enfatiza a amplitude da distância ideológica entre os membros extremos da coalizão e para isso é preciso identificar a exata posição ideológica dos partidos no espectro ideológico. A previsão do modelo é que coalizões com amplitude mínima serão formadas.

O argumento geral da ênfase na ideologia, seja através da adjacência entre os partidos, seja da pequena amplitude entre os extremos, é que coalizões ideologicamente compactas são mais valorizadas porque envolvem menos custos em termos de policy compromises do que as demais opções. Contudo, como esses acordos são alcançados não é enfatizado pela teoria. Aspecto esse comum tanto da abordagem policy-seeking quanto do argumento exclusivamente office-seeking apresentado anteriormente. Essa é uma característica de modelos cooperativos de teoria dos jogos (Laver 1998).

De acordo com Kreps (1990), a diferença entre modelos cooperativos e não cooperativos de teoria dos jogos é que nos modelos de cooperação a unidade de análise normalmente é o grupo (coalizão) especificando o que o grupo pode conseguir, mas sem maior ênfase em como a coalizão afetaria um resultado em particular ${ }^{4}$. Já nos modelos não-cooperativos a unidade de análise é o ator, que tem por objetivo a maximização do seu benefício individual. A cooperação aqui é entendida como resultado do interesse de cada participante individual ${ }^{5}$ (Kreps 1990; Laver 1998).

\footnotetext{
4 "In cooperative games, the players can sign binding agreements. Once the players sign an agreement, they must follow its terms. When
} 
Prisoner's Dilemma is played as a cooperative game, the dilemma disappears. The players can sign an agreement to play $\left(\mathrm{S}_{1} ; \mathrm{S}_{1}\right)$ )" (Morrow 1994, p.111).

5 [Noncooperative approach] considers the actors' incentives in the bargaining as what offers they should make and when they should accept those offers. Rather than ask what rational bargains look like, we ask how rational actors bargain. The noncooperative approach allows us to explore bargaining behavior as well as the final bargaining reached" (idem, p.145).
A emergência dos modelos não-cooperativos de formação de governos de coalizão está também associada à ênfase em variáveis institucionais nas análises, principalmente o papel do formateur, o timming da formação da coalizão ou o número de rodadas para o estabelecimento de um acordo e também o processo de decisão governamental após a formação do governo (Rubinstein 1982; Austen-Smith \& Banks 1988; Baron \& Ferejohn 1989; Laver \& Shepsle 1990; 1996).

Os modelos não cooperativos analisam a formação de governos de coalizão como o resultado de barganhas sequenciais. Uma barganha é uma situação na qual dois indivíduos tem diante de si diversas opções de contrato. Ambos têm interesse em chegar a um acordo, porém seus interesses não são idênticos. $\mathrm{O}$ objetivo passa a ser identificar qual será o acordo, assumindo que os atores são racionais (Rubinstein 1982). Com base nessa definição de barganha, Rubinstein (idem) estabelece o modelo geral para análise da formação de coalizões com base nos atores racionais como unidade de interesse. Nota-se que mesmo tendo interesse na ação coletiva, o cálculo individual é o que importa para a compreensão dos governos a serem formados. A estrutura geral das barganhas sequenciais proposta por Rubinstein é a seguinte:

"Two individuals have to reach an agreement on the partition of a pie of size 1. Each has to make in turn, a proposal as to how it should be divided. After one party has made such an offer, the other must decide either to accept it or to reject it and continue with the bargaining" (idem, p.98).

Como pode ser visto, o modelo de barganhas sequenciais é uma aplicação do famoso jogo "divide the dollar". Trazendo o modelo geral para a análise da formação de governos de coalizão, o prêmio a ser dividido é o governo (ministérios) e esse prêmio possui um tamanho fixo. A barganha se dá em torno de como os partidos dividirão esses ministérios. $k_{n}$ partidos controlam cadeiras no Legislativo e o modelo prevê a barganha apenas entre pares. De forma aleatória, $k_{l}$ é estabelecido como o formateur. Isto é, pode fazer a oferta primeiro. $k_{l}$ oferece uma determinada divisão dos ministérios a $k_{2}$. A lógica de barganha sequencial estabelece que $k_{2}$ tem duas opções, aceitar a proposta de $k_{1}$ ou passar para a próxima rodada, podendo até ele mesmo assumir a posição de formateur e fazer a sua oferta. A sequência se mantém até o governo ser formado (Rubinstein 1982).

Como pode ser visto no modelo descrito acima, ao contrário dos modelos que enfatizam o tamanho ou a ideologia, a proposta das barganhas sequenciais busca especificar explicitamente as regras e procedimentos que orientam o processo de barganha para formação do governo (Martin \& Stevenson 2001). No caso do modelo de Rubisntein (1982), o papel do formateur é fundamental uma vez que esse ator pode usar seu poder de agenda para garantir uma parcela maior na divisão do governo. De fato, esse é o resultado previsto pelo modelo que estabelece a vantagem do formateur em barganhas sequenciais.

A ênfase nas regras que estruturam o processo de formação do governo também é observada no argumento de Baron e Ferejohn (1989), na medida em que estas afetam a ordem na qual os partidos podem fazer a sua proposta. $\mathrm{O}$ diferencial desse modelo está na barganha multilateral em oposição à restrição do modelo de Rubinstein (1982) na análise apenas de pares de partidos. Também de interesse é que o poder de agenda é estabelecido de forma endógena. Nesse caso, os atores têm de formar expectativas quanto às futuras propostas, uma vez que podem ser inferiores do que a proposta sendo considerada. O resultado é semelhante ao do modelo proposto por Rubinstein (1982), "the member recognized to make a proposal neverthless retains some agenda power and recieves more benefits than any other member" (idem, p.1200). 
Um aspecto interessante desses modelos é que apontam a necessidade de levar as regras e procedimentos que governam o processo de formação em consideração. Porém, falham em especificar quais regras e procedimentos são esses. Parte da limitação está na restrição da teoria dos jogos em levar um número elevado de parâmetros em consideração sem perder a simplicidade e capacidade preditiva, isto é, a identificação de situações de equilíbrio.

Uma tentativa de superar essa limitação é desenvolvida por Austen-Smith e Banks (1988), estabelecendo uma conexão entre o papel do formateur e os resultados eleitorais. O modelo fundamenta o poder de agenda, especificando o partido mais votado como o primeiro ator a fazer a oferta. Se a oferta não for aceita, a sequência segue e o segundo partido mais votado tem a prerrogativa de fazer a sua oferta, e assim sucessivamente. A conexão entre formação do governo e as eleições é estendida de forma a incluir a competição interpartidária por votos, antecipando o poder de agenda no estágio de formação de governo.

Carroll e Cox (2007) expandem o modelo de barganha ao considerarem também o estabelecimento de acordos pré-eleitorais entre os partidos, que influenciariam a distribuição de portfólios no momento da formação do governo. De acordo com o modelo, a existência de acordos pré-eleitorais aumenta a proporcionalidade da alocação de portfólios.

Dos modelos apresentados acima podemos observar duas vertentes principais: os modelos baseados na demanda (demand-based models) e os modelos baseados na proposta (proposal-based models) (Ansolabehere et al., 2003). Os modelos de demanda são os que estabelecem a proporcionalidade da distribuição de ministérios e os modelos de proposta são os que identificam a vantagem do formateur. O que os testes empíricos dizem sobre esses argumentos? A Lei de Gamson ou a regra da proporcionalidade é uma das principais regularidades empíricas da Ciência Política. Contudo, a relação não é perfeita e alguns trabalhos de fato identificam uma vantagem do formateur, ainda que pequena e muitas vezes instável (Warwick e Druckman 2001; Ansolabehere et al., 2003).

Um desenvolvimento interessante dessas duas perspectivas é encontrado no argumento de Bassi (2013), que prevê que a vantagem do formateur é dirimida quando há competição endógena pelo papel de fazer a oferta. A competição faz com que o formateur, para ter sua proposta aceita, não ofereça uma distribuição desigual dos ministérios. Contudo, quando a posição de formateur é estabelecida exogenamente, como através do resultado das eleições por exemplo, o ator tem a vantagem para oferecer uma distribuição desigualmente favorável.

Deslocando um pouco o foco do papel do formateur, o desenvolvimento mais recente dos modelos institucionais de formação de governos de coalizão focam as instituições que alocam posições no gabinete diferenciadamente de acordo as preferências dos partidos. Isto é, para além de toda uma literatura que estabelece o governo como composto de posições no gabinete totalmente homogêneas, onde a decisão a ser tomada é exclusivamente quanto ao número de ministérios que cada partido controlará, esses modelos identificam diferenças entre os ministérios, estabelecendo que diferentes partidos possuem preferências por diferentes ministérios (Laver \& Hunt 1992; Warwick \& Druckman 2001).

Diferentes partidos apresentam diferentes preferências por ministérios específicos e isso está totalmente ligado ao fato de que os partidos uma vez no governo controlarão o processo decisório de políticas. Para um partido é de maior interesse controlar o ministério que controlar as decisões mais relevantes para sua constituency. Para o partido verde o ministério do meio ambiente pode 
ser mais importante do que os demais. Para um partido ligado a industriais o ministério da indústria pode ser central. E para todos os partidos a posição de primeiro-ministro é fundamental (Laver \& Hunt 1992; Warwick \& Druckman 2001).

Do ponto de vista empírico, a principal contribuição é apresentada em Laver e Hunt (1992) e reúne os resultados de um survey desenvolvido para identificar a saliência relativa de cada ministério. Trabalho este aprimorado por Warwick e Druckman (2001), que constroem uma medida contínua de saliência ministerial, levando em consideração não apenas a diferença ordinal entre os ministérios, mas também quanto cada ministério é mais importante que os demais.

O argumento da "saliência" dos ministérios traz dois pontos de fundamental importância: primeiro, o "prêmio" a ser dividido não é composto de partes homogêneas e isso deve ser considerado nos cálculos de proporcionalidade. Segundo, admitir que os partidos possuem preferências por determinados ministérios é ressaltar um aspecto muitas vezes esquecido nos governos de coalizão: os partidos conquistam votos de diferentes parcelas do eleitorado, possuindo constituency diferenciada e policy preferences específicas a serem implementadas uma vez no governo. Isso traz a pergunta fundamental: como o processo decisório governamental, isto é, como a influência sobre decisões de políticas afeta quem recebe qual ministério?

O modelo clássico que estabelece esse argumento é o proposto por Laver e Shepsle (1990). Segundo os autores, a formação de um governo de coalizão tem por base o acordo entre os partidos-membros de que uma vez investido no controle de uma pasta ministerial, o partido usará tal controle para implementar políticas mais próximas de suas preferências. Tal argumento prevê a total autonomia dos ministérios, ou como ficou conhecido na literatura, o "governo ministerial", no qual cada ministro é responsável pelas decisões de seu ministério com total autonomia e ausência de interferência dos demais partidos da coalizão.

O equilíbrio da autonomia ministerial é alcançado porque é a única opção crível de formação do governo. Quando um partido assume uma pasta ministerial ele não pode se comprometer, ao menos não de forma crível, a implementar políticas que são contrárias a seus interesses (Laver \& Shepsle 1990; 1994; 1996).

O desenvolvimento do argumento é o princípio da não interferência mútua: cada ministro implementa decisões de acordo com suas preferências nos ministérios e todos os ministros se comprometem a não interferir nas decisões de seus pares. Dito de outra forma, ter total autonomia nas decisões do ministério implica também abrir mão da prerrogativa de interferir nas decisões de outro ministério, mesmo que essas sejam contrárias às suas preferências. A ideia subjacente aqui é a da reciprocidade: ao interferir nas decisões de outro ministério, o ministro pode sofrer retaliação na mesma moeda. Nas palavras de Andweg (2000, p.378), "ministers forgo their right to intervene in other portfolios to protect their own autonomy; if one criticizes the proposal of a colleague, one should expect that colleague to reciprocate likewise".

Esses trabalhos, mesmo se tratando de modelos de formação, já ressaltam a importância do que acontece depois que o governo é formado. Isto é, como as coalizões de fato governam. Preocupando-se com a saliência de diferentes ministérios e também com os compromissos feitos no momento da formação da coalizão sobre como cada partido controlará as decisões circunscritas aos seus ministérios, abrem espaço para uma nova discussão agora com foco na governança das coalizões. 
III.2. Modelos de governança: governo ministerial versus controle mútuo

${ }^{6}$ Governança pode ter se tornado um termo bastante genérico ultimamente, mas neste contexto "it denotes both the practice of governing and the stage in the life cycle of governments that is devoted to policy execution and implementation" (Strom, Muller \& Bergman 2008, p.9).
Os modelos de governança das coalizões têm como ponto de partida uma crítica à concentração excessiva dos estudos no momento da formação do governo de coalizão. Uma conclusão que pode facilmente ser entendida, principalmente a partir dos modelos de barganha, é que uma vez "dividido o dólar" a relação é encerrada e não importa o que cada ator faz com a sua parcela do ganho. Nas palavras de Laver e Shepsle:

"When the executive is considered at all by conventional coalition theories, it is seen not as a decision-making body in its own right, but rather as a prize to be shared out by a winning legislative coalition - a set of perks of office, the most important of which are seats at the cabinet table. [...] Cabinet portfolios, once allocated, are simply consumed as benefits by the legislative parties that hold them" (Laver \& Shepsle 1996, p.12).

Os modelos de governança ${ }^{6}$ buscam problematizar o que acontece depois que a coalizão é formada e depois que os portfólios são distribuídos. Isto é, como as coalizões de fato governam. Invariavelmente, os partidos são vistos como policy-oriented. Em outras palavras, ao contrário do argumento office-seeking de que "simply to get into the executive, almost regardless of the precise distribution of portfolios, is probably the most salient payoff" (Budge \& Laver 1986, p.491), os partidos seriam policy-seekers, maximizando cargos no Executivo como uma forma de influenciar as políticas seja em si ou de forma instrumental como uma estratégia para conseguir votos nas próximas eleições (idem).

Identificada a centralidade das políticas para o jogo político, o foco se desloca para o que acontece após a formação da coalizão, o que até recentemente era ignorado. A crítica de Laver e Shepsle é bastante enfática:

"Discussions of government coalitions have concentrated almost exclusively on the fact that they are coalitions and more or less ignored the fact that they are also governments. Little attention has been devoted to what happens after a government has been formed or to how rational expectations about what will happen influences the formation process itself"' (Laver \& Shepsle 1990, p.873; grifos no original).

Curiosamente, o principal modelo de governança é derivado de um modelo de formação de governos de coalizão: o modelo do governo ministerial (Laver \& Shepsle 1990; 1994; 1996). No modelo original, Laver e Shepsle (1990) argumentam que a divisão do trabalho num governo multipartidário indica que o partido que controla determinado ministério tem poder de agenda e controla as decisões relacionadas àquela determinada policy dimension. O argumento é de uma simplicidade e simultânea inteligência: na ausência de controles externos atores racionais somente podem se comprometer a implementar as decisões que são o seu ponto ideal. Qualquer outro compromisso que busque implementar decisões que não são a sua preferência são promessas não críveis ou, como dizem os autores, cheap-talk.

A lógica do modelo pode ser assim resumida: dois partidos, A e B, negociam a formação de uma coalizão. Reduzindo a negociação a duas dimensões, afirma-se que cada partido possui preferências formadas por cada dimensão e cada uma das dimensões é controlada por um ministério. Por exemplo, dimensão $x$ seria o ministério da fazenda e dimensão $y$ o ministério da saúde. Cada partido é caracterizado por um ponto ideal em cada uma das dimensões, $x_{A} y_{A}$ para o partido $\mathrm{A}$ e $x_{B} y_{B}$ para o partido $\mathrm{B}$, e prefere políticas próximas a seu ponto ideal a políticas mais distantes. O modelo da autonomia ministerial de Laver e Shepsle $(1990 ; 1996)$ prevê que uma vez no governo o partido que controla o ministério implementará seu ponto ideal. Dessa forma, a distribuição específica 
dos ministérios afeta quais coalizões são "viáveis". A regra majoritária estabelece que uma nova coalizão será formada quando apresentar o apoio da maioria em detrimento do status quo. As curvas de indiferença dos partidos indicam todas as políticas preferidas ao $S Q$ (Laver \& Shepsle 1990; 1996; Martin \& Vanberg 2011) (Figura 1).

Como pode ser visto na Figura 1, a opção que satisfaz o critério de alcançar o apoio da maioria frente ao status quo é a coalizão $x_{B} y_{A}$, isto é, o governo no qual o partido B controla o ministério da fazenda e A controla o ministério da saúde. Nota-se que a precisa distribuição dos ministérios é fundamental, uma vez que a coalizão $x_{A} y_{B}$, mesmo contando com exatamente os mesmos participantes, não é viável já que não está na intersecção entre os dois partidos.

O que é importante notar nesse modelo é que ele endogeniza o processo de distribuição dos portfólios. Isto é, a coalizão é formada com base na expectativa dos partidos sobre as políticas que serão implementadas uma vez formado o governo. Como os partidos somente podem se comprometer a implementar os seus pontos ideais, o acordo da coalizão se auto reforça e é compatível com os incentivos sobre os atores (idem).

O modelo da autonomia ministerial ou portfolio allocation de Laver e Shepsle $(1990 ; 1996)$ é central na literatura e se tornou a referência com a qual os demais modelos dialogam. Com base nesse modelo foi desenvolvida aplicação específica na explicação da alocação do orçamento, constituindo um argumento central na economia política dos governos de coalizão. De acordo com o argumento, cada ministro setorial usaria o seu poder de alocação orçamentária no controle do ministério para distribuir benefícios para o seu eleitorado. Uma vez que cada ministro possui o mesmo controle sobre o orçamento (não interferência mútua) e tem como objetivo o sucesso eleitoral, o resultado seria um problema de recursos comuns ou common pool problem. Cada ministro busca manter os seus gastos e os benefícios distribuídos para o eleitorado, transferindo para os demais ministros a preocupação de manter as contas do governo sob controle. Uma vez que todos os ministros realizam o mesmo cálculo racional, a tendência é que governos de coalizão levem a altos gastos

Figura 1 - Equilíbrio da Autonomia Ministerial

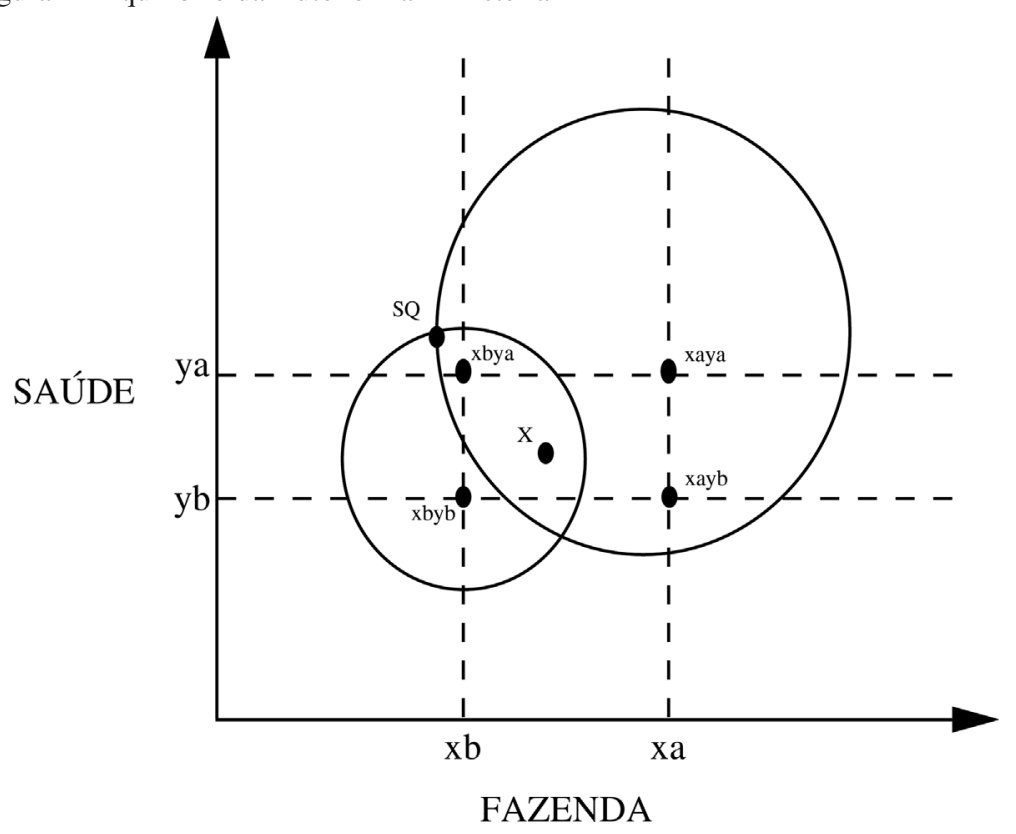

Fonte: adaptado de Martin e Vanberg (2011). 
públicos e descontrole fiscal. Adicionalmente, quanto maior o número de partidos no governo, maior o déficit (Bawn \& Rosembluth 2006; Persson, Holland \& Tabellini 2007; Hallerberg \& Von Hagen 1997).

Mesmo se tratando de um modelo fundamental, o modelo do governo ministerial se concentra no aspecto delegativo dos governos de coalizão, não analisando os mecanismos de controle estabelecidos para reduzir as perdas de agência nesse tipo específico de governo no qual essas perdas são exacerbadas.

Como alternativas empíricas aos modelos da autonomia ministerial, Laver e Shepsle (1994) propuseram um esquema no qual os governos de coalizão poderiam ser classificados de acordo com o seu modelo de decisão. Segundo Laver e Shepsle (1994), há seis modelos possíveis: o governo burocrático, no qual a composição da burocracia determina as políticas adotadas; o governo legislativo, no qual todas as decisões sobre políticas são tomadas pela legislatura; o governo do primeiro-ministro, no qual as preferências do primeiro ministro determinam as políticas adotadas; o governo do partido, em que partidos bem organizados e disciplinados, ao controlar o governo, controlam as decisões políticas tomadas; governo do gabinete, em que as decisões são tomadas coletivamente; por último, o governo ministerial, no qual as políticas adotadas por cada ministério refletem as preferências do ministro que lidera o ministério.

Nota-se que no governo da burocracia a política em si não é relevante, uma vez que mudanças na composição política do governo não alteram as decisões tomadas e que o modelo do governo legislativo desloca o foco para o Legislativo e torna nula a relevância do Executivo como instância de tomada de decisão. Os demais modelos de fato indicam o Executivo como arena de barganha e decisão. A evidência empírica mobilizada a partir de estudos de caso traz elementos a favor da autonomia ministerial. Porém, levando-se em consideração a importância do gabinete como instância de decisão coletiva, uma vez que o ministro individualmente não pode ir de encontro ou desafiar as decisões do gabinete. Nesse sentido, há evidência empírica a favor do modelo de autonomia ministerial. Contudo, essa autonomia é bem mais restrita do que inicialmente proposta no modelo inicial de Laver e Shepsle (1990). Concentrando-se principalmente no poder de agenda dos ministérios na sua área de atuação, contudo, limitado pelo poder coletivo do gabinete.

O modelo da autonomia ministerial se tornou dominante. Contudo, a discussão sobre as condições dessa autonomia e os mecanismos de formulação de uma agenda coletiva ou de controle mútuo entre os parceiros de coalizão se tornou emergente. De acordo com Thies:

"The ministerial government model represents a worst-case scenario in the face of interparty delegation problems, for two reasons. First, it is risky in the presence of ex ante uncertainity about the full range of decisions that ministers will make during the life of the government. Second, it is subotimal, in that all coalition partners can benefit more from delegation if each party's ministers can be reined in; they can implement a policy package that is Pareto superior to that implemented by ministerial government" (Thies 2001, p.581).

Segundo Martin e Vanberg (2011), o principal aspecto que diferencia o processo decisório dos governos de coalizão é que os partidos governam juntos, mas disputam eleições separadamente. Nesse sentido, os partidos possuem incentivos para implementar seu ponto ideal. Porém, os demais partidos do governo são responsabilizados pelas decisões tomadas por cada ministro individualmente em sua área de atuação. Ou seja, as decisões seriam individuais e a responsabilidade coletiva. Com base nesse dilema dos governos de coalizão, mesmo não sendo possível rejeitar a autonomia ministerial devido ao controle da agenda exercido pelos ministros, os partidos possuem incentivos para buscar 
o controle mútuo e assim gerar um equilíbrio Pareto superior como apresentado na Figura 2.

Na Figura 2, o X representa uma solução na qual os partidos se comprometem a implementar políticas que não são seu ponto ideal, mas que se tornam uma solução na qual a coalizão coletivamente seria beneficiada. De acordo com Martin e Vanberg (2011), o dilema dos governos de coalizão é justamente identificar formas de superar "the inherent tension between their collective interest in mutual accomodation and their individual incentives to pursue their particular policy objectives" (idem, p.4; grifos no original).

Contudo, quais seriam as formas de estabelecer tais soluções de equilíbrio? Isto é, como é possível induzir decisões coletivas que não são os pontos ideais dos partidos que compõem o governo? De acordo com o argumento de Laver e Shepsle (1990; 1996), a autonomia ministerial é o resultado previsto, uma vez que não necessita de mecanismos externos para ser reforçada. Assim, para argumentar a favor do equilíbrio Pareto superior da acomodação das preferências dos parceiros da coalizão, é preciso identificar os mecanismos através dos quais é possível o controle mútuo. Tal preocupação com mecanismos capazes de minimizar os resultados negativos do cálculo racional individual tem por base a incorporação do desenho das instituições como aspecto relevante na explicação do funcionamento dos governos de coalizão.

Strom, Muller e Bergman (2000) propõem olhar para os coalition agreements. Esses acordos, normalmente formulados pelos partidos no momento de formação da coalizão como um dos elementos da barganha, especificam políticas a serem iniciadas, decisões a serem tomadas e implementadas pelo gabinete, tornando-se uma forma de restringir a autonomia ministerial e estabelecer resultados coletivamente positivos de forma ex-ante. Esses acordos, que em grande parte das democracias parlamentaristas são escritos e autoritativos, podem especificar um grande número de situações engessando ou cristalizando um conjunto de decisões contra a autonomia dos agentes responsáveis pela área. A análise dos acordos mostra que políticas específicas e regras de resolução de conflitos, como através de comissões ou de inner cabinets, são os principais

Figura 2 - Policy Compromise como Solução Pareto Superior no Governo de Coalizão

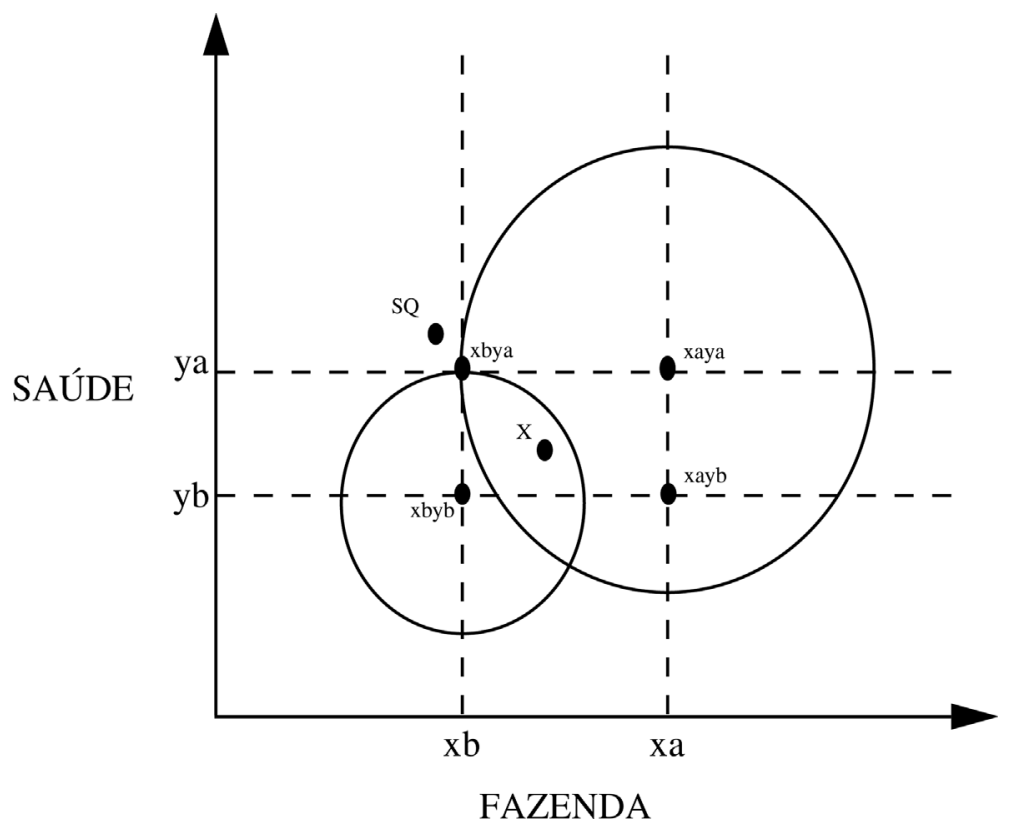

Fonte: adaptado de Martin e Vanberg (2011). 
tópicos, indicando a preocupação dos atores com o controle dos ministros no processo decisório.

Um mecanismo de controle citado por Muller, Strom e Bergman (idem), mas desenvolvido na sua total extensão por Thies (2001) é o uso da indicação dos ministros-júnior como uma forma de manter os parceiros da coalizão sob controle. De acordo com Thies (idem), a "administração" da delegação aos ministros seria uma opção superior e viabilizada através da indicação de ministros-júnior de outro partido que não o do ministro, como um contraponto ao controle absoluto do chefe do ministério e também como uma fonte de informação alternativa para os parceiros da coalizão.

A indicação de ministros-júnior de partidos que não o do ministro reduz a vantagem informacional do ministro e desempenha assim duas tarefas: a de monitoramento das ações dos ministros e a de freio sobre a sua capacidade de implementar decisões. Dessa forma, o poder de agenda dos ministros frente ao gabinete é diminuído dando a este a capacidade de manter as decisões do governo sob controle. A indicação de ministros-júnior seria um mecanismo para alcançar o resultado Pareto superior em termos de políticas. O modelo de Thies (idem) prevê que esse mecanismo será utilizado quando: 1) os ministros não forem "constrangidos" por outros mecanismos institucionais como por exemplo um primeiro ministro forte e com grande assessoramento organizacional direto; 2) quando o portfólio for de maior saliência; 3) quanto maior for a incerteza. Essas condições implicam que a indicação de ministros-júnior apresenta custos e deve ser usada estrategicamente.

Carroll e Cox (2012) analisam como os presidentes das comissões no parlamento podem se tornar "sombras" (shadow minister) dos ministros e assim monitorar as decisões tomadas por cada ministério no gabinete e por conseguinte trazer as decisões do governo para mais próximo das preferências da coalizão como um todo e não só do ministro específico. Para tal mecanismo ser utilizado para o monitoramento é preciso existir correspondência entre os ministérios e as comissões. Dito isso, os autores argumentam que os ministros serão monitorados pelos presidentes das comissões no Legislativo quando (i) o ministro apresentar fortes desacordos com os outros partidos da coalizão quanto às políticas que devem ser adotadas e (ii) quando o presidente da comissão é forte.

Martin e Vanberg $(2004 ; 2011)$ aprontam o papel do parlamento nas democracias parlamentaristas como uma arena decisória alternativa, na qual os conflitos não resolvidos ou a assimetria informacional entre os parceiros da coalizão tem uma nova oportunidade de discussão e revisão dos acordos. De acordo com os autores, os parceiros da coalizão estão envolvidos num jogo de sinalização envolvendo seus eleitores. Dessa forma, o ministro, ao controlar uma determinada pasta, buscará usar a sua posição privilegiada para sinalizar ações para o seu eleitorado. Assim, o equilíbrio da coalizão está sob constante ameaça uma vez que as políticas implementadas por um ministério como uma forma de satisfazer o seu eleitorado podem ferir o eleitorado de um parceiro da coalizão.

Como uma forma de reduzir os riscos da delegação, os membros da coalizão podem remeter ao Legislativo como instituição de escrutínio e mudança das iniciativas legislativas do gabinete. Nesse sentido, as bancadas dos partidos e membros da coalizão podem observar as decisões de ministérios controlados por outros partidos, utilizando a prerrogativa de modificar os projetos recebidos do gabinete e, assim, manter as decisões do governo mais próximas das preferências da coalizão como um todo e não só do partido que controla o ministério específico (Martin \& Vanberg 2004; 2011). 
Martin e Vanberg (2013) utilizam o mesmo argumento do constrangimento institucional sobre o cálculo racional individual para explicar como os governos de coalizão podem restringir o impulso "gastador" de seus ministros e manter as contas do governo sob controle. Segundo os autores, o common pool problem somente se impõe quando regras e procedimentos não regulam o comportamento dos ministros. Uma vez que regras de decisão coletiva ou mecanismos de escrutínio são impostos, os incentivos para o aumento dos gastos públicos são mitigados.

Enquanto os modelos de formação se preocupam com quem integra o governo, as análises sobre a governança da coalizão se preocupam com o exercício do governo ou como as decisões de fato são tomadas uma vez formada a coalizão. Da literatura sobre formação entendemos que o tamanho importa e que a proporcionalidade é a regra. Contudo, a ideologia e as instituições também são relevantes para explicar quem ganha o quê, quando e por que no jogo da coalizão. Das análises sobre governança podemos identificar que o governo ministerial é esperado na ausência de mecanismos de controle mútuo. Para alcançar o equilíbrio Pareto superior é preciso formular regras e procedimentos que mantenham os parceiros da coalizão sob controle.

\section{Entre o Executivo unipartidário americano e a coalizão multipartidária europeia: como explicar o Executivo no presidencialismo de coalizão?}

Para além da clássica dicotomia entre presidencialismo e parlamentarismo, o presidencialismo de coalizão se apresenta como uma variante institucional que combina a estrutura hierárquica centrada no presidente com a formação de coalizões multipartidárias. Como então explicar o Poder Executivo nesse sistema? Como os argumentos desenhados para explicar o Poder Executivo no presidencialismo americano e os governos de coalizão do parlamentarismo europeu podem contribuir para o seu entendimento? E ainda, quais fatores impedem a apropriação direta dessas abordagens? Aqui são apresentados os argumentos formulados para explicar o presidencialismo de coalizão, enfatizando a importância de aproveitar as contribuições dos dois lados do Atlântico.

Explicar o funcionamento do Executivo nos sistemas presidencialistas de coalizão se mostra uma tarefa desafiadora. Apesar de não ser um fenômeno restrito ao Brasil, já que podemos observar a conjunção entra a forma de governo presidencialista e a formação de coalizões em países da América Latina como Chile e Uruguai e também em outros continentes como na África, grande parte dos modelos teóricos são formulados para explicar ou o funcionamento do Executivo unipartidário americano ou os governos de coalizão nas democracias parlamentaristas europeias (Melo \& Pereira 2013).

Nas análises do sistema político americano, mesmo considerando os custos associados à delegação do presidente para os seus ministros, esses custos são de outra ordem quando consideramos que no presidencialismo de coalizão a tomada de decisão envolve vários partidos com objetivos eleitorais diferentes.

No caso das análises do funcionamento dos governos de coalizão em sistemas parlamentaristas, a própria noção de "formação" de um governo de coalizão no presidencialismo não pode ser diretamente aplicada, uma vez que o chefe do Executivo é eleito diretamente e o governo será estabelecido formada a coalizão ou não. Da mesma forma, não podemos falar em dissolução do gabinete ou da legislatura em situações de conflito, o que afeta diretamente os objetivos e o poder de barganha dos atores no presidencialismo.

Nesse sentido, trabalhos sobre o presidencialismo americano e os governos de coalizão no parlamentarismo trazem grandes contribuições e insights importantes para pensar o presidencialismo de coalizão. Porém, as diferenças institu- 
cionais devem sempre ser consideradas no uso dos conceitos e dos indicadores de ambas literaturas. Feita esta ressalva, como os trabalhos específicos sobre o presidencialismo de coalizão vêm incorporando essas discussões sobre o funcionamento do Executivo? Esse sistema está associado a países com desenvolvimento da Ciência Política empírica bastante recente, de forma que trabalhos sobre o funcionamento do Executivo são ainda incipientes. Contudo, o acúmulo teórico já começa a ser observado. Podemos aqui dividir os trabalhos que vem analisado o Poder Executivo como arena de interesse em dois conjuntos principais: primeiro, os estudos sobre a composição do governo, e aqui estão incluídos os trabalhos sobre a formação de governos de coalizão, a coalescência dos governos formados e também as indicações políticas tanto para cargos ministeriais como para a burocracia mais ampla. Segundo, os estudos sobre a organização do Executivo, que vem apresentando foco principal no papel da presidência, seja como variável dependente ou como variável independente.

IV.1. Análises sobre composição

Até recentemente, ainda que de forma implícita, grande parte dos trabalhos que se referiam ao Poder Executivo no Brasil focavam exclusivamente a figura do presidente: a ideologia do presidente, a agenda do presidente ou os poderes do presidente. Contudo, uma agenda vem se formando no sentido de ir além dessa visão do Executivo como ator unitário focado no presidente, olhando para esse poder como arena decisória na qual a composição e estrutura organizacional importam.

O trabalho fundamental sobre o Executivo nas américas é o de Amorim Neto (2006a) sobre a composição dos governos e sua relação com a estratégia do presidente ou o "cálculo presidencial". De acordo com a essa contribuição fundamental, o presidente, no início do seu mandato, tem uma escolha a fazer quanto ao tipo de governo que formará. Essa escolha está condicionada ao tipo de agenda legislativa que o presidente decide implementar: uma agenda legislativa a ser passada pelo Congresso, isto é, composta de projetos de lei e de emendas constitucionais requer um governo de gabinete majoritário, de alta partidarização e alta coalescência. Quando a opção é pelo governo unilateral, no caso do Brasil por meio do uso de medidas provisórias, o tipo de governo é o gabinete minoritário, de baixa partidarização e coalescência.

A análise se dá com base no cálculo presidencial: qual o custo e o benefício associados a cada curso de ação. Um governo majoritário, composto de apoio majoritário, com ministros vinculados a partidos políticos e não ministros técnicos de confiança do presidente e a alta coalescência que significa a proporcionalidade da representação do partido no gabinete ao seu tamanho no Congresso incentiva a relação próxima entre Executivo e Legislativo e o apoio dos partidos que compõem o governo à agenda legislativa do presidente. Ao contrário, o governo minoritário, com baixa partidarização e baixa coalescência está associado ao maior isolamento e ação unilateral do presidente em relação ao Legislativo.

A abordagem proposta por Amorim Neto (idem) trouxe para o estudo do presidencialismo de coalizão argumentos desenvolvidos para explicar a composição do governo em sistemas parlamentaristas, notadamente a aplicação da Lei de Gamson quanto à proporcionalidade da distribuição de portfólios. $\mathrm{O}$ autor descobre que a proporcionalidade nos sistemas presidencialistas varia expressivamente, de acordo com o cálculo presidencial. Contudo, essa proporcionalidade não chega aos expressivos valores observados nas democracias parlamentaristas. Provavelmente devido ao fato de o presidencialismo infringir uma das condições da Lei de Gamson, a existência de um ator que deve ser incluído em toda e qualquer coalizão formada: o partido do presidente. Nesse 
sentido, de acordo com a Lei de Gamson, é esperado que o partido do presidente reivindique parcela do governo maior que a sua contribuição em termos de cadeiras no Legislativo.

Carroll (2007), num dos poucos trabalhos a integrar sistemas presidencialistas e parlamentaristas num modelo de distribuição de portfólios, aponta para um aspecto de extrema importância no presidencialismo: o impacto dos acordos pré-eleitorais sobre a formação da coalizão e distribuição de ministérios entre os parceiros. De acordo com o autor:

"Pre-election alliances have become governments in many competitive regimes with presidential cabinet influence, particularly in Brazil, Chile, and Uruguay. Presidential alliances (...) revolve around competition for the slate of portfolios and involve electoral cooperation, a common label (the presidential candidate), and agreements to divide the spoils of government" (idem, p.46).

Um elemento acerca da distribuição de portfólios ainda não explorado para o caso do presidencialismo de coalizão é a dimensão qualitativa da distribuição precisa dos portfólios, ou qual partido controla qual ministério e por quê. A ausência é tanto teórica, no sentido de desenvolvimento de argumentos sobre a precisa distribuição de pastas, quanto empírica, no sentido de propostas de mensuração da saliência dos ministérios.

A partir da identificação da possibilidade de governos de coalizão no presidencialismo (Cheibub 2007) e também o cálculo presidencial que orienta a sua composição (Amorim Neto 2006a), estudos começaram a se desenvolver em outras frentes. Uma dessas é a análise da formação de governos de coalizão inspirados pelos estudos clássicos de formação apresentados anteriormente. Pouco foi feito ainda no sentido de explicar o estágio anterior da distribuição de ministérios, identificando quais partidos integrarão a coalizão e por quê. Uma contribuição é a de Alemán e Tsebelis (2011), que analisam o processo de formação de coalizões nos sistemas presidencialistas. Os autores identificam que o presidente tende a incluir partidos ideologicamente próximos na coalizão. $\mathrm{O}$ argumento explora também o impacto das instituições, identificando o impacto da balança de poder entre Executivo e Legislativo sobre a formação e composição da coalizão.

Explorando o tema da indicação dos ministros e suas características, Inácio (2013) analisa os determinantes da indicação de políticos experientes ou políticos novatos/tecnocratas para posições nos ministérios no Brasil. $\mathrm{O}$ argumento tem por base uma estratégia de retenção e projeção de quadros do partido através de um cargo nacional. Os resultados indicam que a trajetória partidária é fundamental para explicar a seleção de políticos pelo partido para ocupar cargos no gabinete. A partir de tema similar, a indicação para cargos nos ministérios, Dávila, Lavados e Avendño (2013) analisam a relação entre expertise e ocupação de ministérios em áreas específicas no Chile. Como resultado os autores apontam a correlação entre formação acadêmica e a ocupação de ministérios na área econômica.

Deslocando o foco para a politização da burocracia no presidencialismo de coalizão, Praça, Freitas e Hoepers (2011) analisam a indicação de filiados políticos para os cargos de confiança na burocracia do Executivo brasileiro. $\mathrm{O}$ argumento é que a indicação política para cargos de confiança seria um tipo de recurso à disposição do presidente para administrar a coalizão, para além de emendas orçamentárias e a distribuição de ministérios. Os autores identificam que o uso de indicações políticas varia expressivamente de acordo com o ministério e que não há proporcionalidade partidária na distribuição desses cargos. Aqui o argumento desenvolvido se assemelha ao proposto por Lewis (2009), das indicações políticas como instrumento de patronagem e não de controle político. 
Para além da composição política do governo e da distribuição de cargos nos ministérios, um tema que vem chamado a atenção dos pesquisadores sobre o presidencialismo de coalizão são os desafios do processo decisório num sistema composto pela hierarquia presidencial, mas que conta com múltiplos partidos com diferentes preferências e objetivos eleitorais na sua estrutura. A próxima subseção analisa as principais contribuições nesse tema.

\section{IV.2. Análises sobre organização}

As análises sobre organização ou processo decisório do Executivo no presidencialismo de coalizão vem majoritariamente focando o papel da presidência "by resorting to what constitutes the undisputed benchmark for such a feat: the literature on the US presidency" (Bonvecchi \& Scartascini 2011, p.4). As análises sobre a presidência representam a primeira experiência no sentido de acúmulo teórico sobre a dinâmica interna do Executivo, olhando para além da figura do presidente. Aqui tem-se a preocupação com como as decisões são tomadas e como o governo de fato governa. Como mencionado, a influência maior é a literatura sobre a presidência institucional, com excepcional referência ao trabalho de Moe (1985) sobre a presidência politizada. Com poucas exceções, os termos do debate se referem as categorias propostas por Moe, principalmente a centralização das decisões na presidência.

Bonvecchi (2014) propõe a interessante classificação sobre os estudos sobre a presidência entre aqueles que analisam a presidência como variável dependente, isto é, que buscam explicar as características da presidência em diferentes contextos, e aqueles que buscam analisar o impacto da presidência sobre o processo decisório, como por exemplo a relação entre o presidente e os seus ministros. Essa classificação será aqui utilizada para analisar os trabalhos sobre a organização do Executivo no presidencialismo de coalizão.

Sobre os estudos focados na presidência Bonvecchi argumenta:

"La investigación sobre el centro presidencial en América Latina se encuentra todavía en su infancia. El conjunto de trabajos sobre el tema es aún pequeño y limitado en sus alcances: trata apenas sobre um puñado de países y se ocupa de períodos históricos relativamente cortos y recientes. Sin embargo, las perguntas planteadas, las teorías que las sustentan y las metodologías empleadas colocan a este incipiente campo de estudio en condiciones de producir investigaciones consistentes y de amplia base comparativa, que contribuyen significativamente a la expansión del conocimento sobre la coordinación del Poder Ejecutivo" (idem, p.14).

Sobre a perspectiva da presidência como variável dependente, o objetivo é descrever e explicar a composição, funções e evolução dos órgãos de assessoramento direto do presidente. A ideia é que essas características variam de acordo com as preferências do presidente e o contexto político no qual os atores interagem. Nesse sentido, o Executivo é visto como uma arena decisória complexa e com uma lógica própria, como muitos anos antes o Legislativo passou a ser visto.

Nessa perspectiva, o trabalho de Inácio (2006) foi pioneiro ao apontar as especificidades do presidencialismo de coalizão. A ideia desenvolvida é que a institucionalização da presidência pode ser considerada uma estratégia do presidente para lidar com os custos de transação de um governo multipartidário. $\mathrm{O}$ argumento central é que o aumento dos quadros de apoio direto ao presidente e a diferenciação dos órgãos, constituindo a institucionalização da presidência, é função direta do aumento da complexidade dos governos de coalizão. Para fazer frente aos desafios de coordenação com coalizões cada vez mais complexas, o presidente transforma a estrutura da presidência para constituir uma fonte de informações confiável frente aos dilemas da delegação. 
Em sua análise sobre o México, Méndez (2007) desenvolve um argumento que pode ser um interessante complemento ao argumento do desenvolvimento da presidência no presidencialismo de coalizão com base na complexidade da barganha entre os atores num governo multipartidário. Segundo o autor, a presidência no México não sofreu expressivo desenvolvimento devido a reduzida complexidade e ao baixo custo de coordenação no governo. Em suas palavras:

“[...] los presidentes mexicanos han visualizado como mucho más 'cercanas' y 'dependientes' a las secretarias de Estado y a sus funcionarios altos e intermedios (analistas, directores de área, etc.). El que éstos tuvieran nombramientos 'de confianza' y estuvieran más accesibles ha evitado que el presidente se vea en la necessidad de tener en las oficinas de la residencia presidencial um grupo más grande de analistas y directores para el impulso y coordinación de las políticas públicas" (idem, p.855).

Este é um ponto interessante que mostra a variação no tamanho e na diferenciação da presidência em função da complexidade do contexto de decisão. Ainda segundo o autor, uma vez que a tomada de decisão se tornou mais complexa com a inclusão de mais interesses, a presidência começou a se ampliar. Sobre o caso do Uruguai, Lanzaro (2013) aborda o tema pouco explorado nessa literatura, que é o estilo presidencial. Enquanto um estilo "hierárquico" incentiva o fortalecimento da presidência, o estilo "arbitral" aumenta a tomada de decisão horizontal e o compartilhamento de poder com ministros centrais e também com o conselho de ministros.

Com o objetivo de tornar a discussão sobre a presidência mais clara e sistemática, Carmelo e Coutinho (2014) propõem uma interessante tipologia de arenas decisórias do Poder Executivo. Segundo os autores, o Executivo é formado da arena presidencial, composta das unidades internas da presidência; a arena governamental, composta das unidades internas do gabinete e instâncias interministeriais; e a arena setorial, composta das unidades internas dos ministérios. Essa tipologia é importante para estudos comparativos no sentido de diferenciar as arenas do Executivo e identificar quais fatores explicam a variação em quais tipos de arena executiva.

Deslocando o foco da assistência direta formal, Siavelis (2010) analisa as estruturas informais. Nas palavras do autor, "presidents often build or rely upon informal networks of supporters and advisors that help them structure relations with congress, protect their image, and navigate difficult political waters by providing presidents avenues of influence and power that are informal in nature" (idem, p.3). O argumento desenvolvido é que a estrutura das organizações informais do Executivo ajuda a explicar quando a distribuição formal de ministérios alcançará o objetivo de estabelecer um consenso multipartidário no processo decisório. Isto é, para além da distribuição formal dos ministérios, é preciso identificar quem de fato tem o poder de decidir: os ministros ou a assistência direta ao presidente. Para tanto, é preciso olhar também para as estruturas informais do Executivo e seu processo decisório.

Lameirão (2011) faz uma densa apresentação da evolução do papel da Casa Civil na presidência brasileira. Vieira (2014) analisa, com base no caso brasileiro, como o conflito entre os atores intra-executivo afeta a criação de estruturas centralizadas na presidência, em oposição a delegação para os ministérios. Numa primeira contribuição no sentido de política comparada para o estudo da presidência, Inácio e Llanos (2014) testam o argumento inicialmente proposto por Inácio (2006), para o Brasil, de que governos de coalizão aumentam a complexidade das barganhas e os custos de transação no processo decisório, influenciando o aumento e diferenciação das estruturas da presidência. As autoras encontram precisamente que quanto maior o número de partidos na 
coalizão, maior será a institucionalização da presidência devido aos custos de governo.

Para além dessas análises que têm como objetivo explicar a estrutura e composição da presidência, isto é, análises que focam a presidência como variável dependente, há também o enfoque na presidência como fator explicativo do comportamento dos atores, isto é, como variável independente. Essas abordagens preocupam-se mais com o processo decisório de fato e principalmente como o presidente se relaciona com os seus ministros.

Martinez-Gallardo (2010) é uma das primeiras a chamar a atenção para o papel desempenhado pelos ministros no processo decisório do Poder Executivo. Segundo a autora, "the vast authority that is delegated to cabinet ministers in Latin American presidential countries stands in sharp contrast with the lack of academic work on cabinet politics and its influence on policymaking" (idem, p.119). O argumento é que, apesar de no presidencialismo os ministros apresentarem poderes formais limitados, constituindo-se basicamente em conselheiros do presidente, no processo decisório desempenham papel fundamental por três razões: 1) tem o poder de agenda e expertise para iniciar legislação de origem executiva; 2) são responsáveis pelo acompanhamento da tramitação dos projetos de iniciativa do Executivo no Legislativo; 3) são o ator central na implementação de políticas.

Avançando na discussão sobre o papel dos ministros no processo decisório do Executivo, Rennó e Gaylord (2012) analisam o Brasil e exploram a autoria das iniciativas legislativas do Executivo, buscando identificar padrões de concentração e compartilhamento da agenda legislativa com os partidos da coalizão. Sob quais condições o presidente compartilha a agenda legislativa com os partidos da coalizão e quando o presidente concentra a formulação nas mãos do seu próprio partido? Os autores identificam que critérios partidários de fato importam e podemos observar uma concentração da agenda legislativa no partido do presidente, mesmo sob presidencialismo de coalizão.

Fortemente influenciada pelo argumento proposto por Rudalevige (2002) da centralização contingente, Batista (2013) identifica que no processo de formulação da agenda legislativa o presidente tem duas opções: centralizar a decisão na presidência ou delegar para os ministros. Cada opção apresenta custos de transação e o presidente decide de acordo com as características da matéria e do ministro em questão. Os resultados para o caso brasileiro mostram a importância da distância ideológica para a escolha do presidente. Adicionalmente, aponta a centralidade dos ministérios no processo decisório e a atuação contingencial da presidência no controle das decisões.

Analisando o uso da indicação política como instrumento de controle presidencial, Pereira et al. (2013) apresentam uma análise da estratégia do presidente na indicação de ministros-júnior, ou, como é chamado no Brasil, secretários-executivos. $\mathrm{O}$ argumento desenvolvido é uma aplicação do modelo proposto por Thies (2001) da indicação de ministros-júnior de um partido diferente do partido do ministro no sentido de controlar as ações do ministro e manter as decisões do governo próximas das preferências do presidente. Os autores encontram que quanto maior a distância ideológica entre o presidente e o ministro, maior a chance de indicação de um ministro-júnior alinhado com as preferências do presidente.

Com foco específico na influência dos ministros no processo decisório do Executivo brasileiro, Batista (2014) analisa o controle ministerial sobre as iniciativas legislativas e sobre a alocação orçamentária, identificando que quanto maior a distância ideológica entre o presidente e o ministro, menor a influência do ministro no processo decisório do Executivo. Adicionalmente, é 
identificado que o presidente tende a concentrar a formulação da agenda legislativa no seu próprio partido, delegando a alocação do orçamento para os demais partidos da coalizão.

A análise do Executivo no presidencialismo de coalizão é bastante recente e ainda incipiente. Contudo, já mostra desenvolvimento de argumentos relevantes e importante acúmulo teórico. Outro aspecto importante é a preocupação com o teste empírico de hipóteses teoricamente fundamentadas. $\mathrm{O}$ acúmulo de conhecimento vem sendo alcançado com base no diálogo direto seja com a literatura sobre a presidência americana seja com a literatura sobre os governos de coalizão no parlamentarismo europeu, facilitando a comparação e fundamentando a generalização. Contudo, esse diálogo não é feito de forma irrestrita, tendo os autores a preocupação de identificar os aspectos específicos do presidencialismo de coalizão.

Essa discussão dos argumentos desenvolvidos especificamente para o presidencialismo de coalizão mostra que se trata de um tema ainda incipiente, porém com grandes perspectivas de desenvolvimento. A transição para o entendimento do Executivo como estrutura de poder em si ainda não foi completada, mas questões relevantes começam a se estabelecer, constituindo-se numa grande e importante agenda em aberto.

\section{Conclusões}

O Poder Executivo desempenha um papel fundamental nas democracias contemporâneas. Contudo, diferenças institucionais entre presidencialismo e parlamentarismo importam e é possível identificar essas diferenças também no funcionamento do Executivo. Além dessa dicotomia clássica entre presidencialismo e parlamentarismo, temos o presidencialismo de coalizão como forma institucional que combina a hierarquia centrada no presidente da forma presidencialista com a formação de governos multipartidários dos sistemas parlamentaristas de coalizão.

O objetivo deste ensaio foi apresentar como a literatura vem olhando para o funcionamento interno do Executivo como arena de tomada decisão nessas diferentes formas. Especificamente, buscou-se recuperar, sistematizar e analisar a literatura sobre o funcionamento interno do Executivo no presidencialismo americano, no parlamentarismo de coalizão europeu e no presidencialismo de coalizão. O foco está no papel dos atores, no processo decisório e nas principais características enfatizadas em cada sistema.

Nas análises sobre a presidência americana, o elemento inicial do debate é a pergunta: tendo em mente que nos sistemas presidencialistas o presidente é o chefe absoluto do Poder Executivo, personalidade e estilo individual determinam os resultados ou instituições, regras e procedimentos constrangem e orientam o comportamento gerando regularidades? Com base na resposta a essa pergunta, duas grandes correntes de estudo podem ser observadas: o foco na personalidade ou habilidades pessoais de liderança do presidente e análises sobre a presidência institucional, nas quais o Executivo é visto de forma mais ampliada e regras e procedimentos importam para os resultados.

Já as teorias sobre governos de coalizão formuladas para explicar os sistemas parlamentaristas europeus são racionalistas no seu núcleo. A composição do Executivo e o seu funcionamento são resultado de uma barganha entre atores racionais maximizando a participação em algum tipo de prêmio. A literatura pode ser dividida em dois focos principais: as análises sobre a formação de coalizões e a literatura sobre governança. A formação de coalizões tem por base o compartilhamento de um prêmio: o governo. O prêmio pode ser dividido em unidades menores - os portfólios - e o principal objetivo dos partidos é 
maximizar a sua parte do prêmio, controlando um conjunto de ministérios. No entanto, o que os partidos fazem com a sua parte do prêmio também importa e a governança da coalizão, ou seja, como as coalizões de fato governam, tornou-se o tópico emergente. O ponto é identificar quem decide em governos de coalizão. Dois argumentos são dominantes: o argumento do governo ministerial e o argumento do controle mútuo.

Entre o presidencialismo americano e o parlamentarismo europeu está o presidencialismo de coalizão, sobre o qual aparece um número cada vez maior de contribuições. A figura do presidente é fundamental e parte dos argumentos sobre a presidência americana podem aqui ser incorporados. Contudo, o processo decisório em governos de coalizão impõe custos que somente uma análise complexa pode abarcar. Das análises do presidencialismo americano nós aprendemos que o presidente está no centro do processo de tomada de decisão. Regras e procedimentos também são importantes para constranger o comportamento e podem ser um instrumento fundamental para o presidente manter controle sobre as decisões do governo. Das abordagens dos governos de coalizão no parlamentarismo europeu compreendemos que o Executivo é uma arena complexa de barganha entre atores. O processo decisório importa e o governo ministerial é esperado quando mecanismos de controle e monitoramento não estão em funcionamento.

Incorporando essas contribuições da literatura sobre o Executivo unipartidário focado no presidente do presidencialismo americano e sobre o Executivo multipartidário do parlamentarismo europeu, a crescente literatura sobre o funcionamento interno do Executivo no presidencialismo de coalizão vem adquirindo cada vez mais acúmulo teórico, comparabilidade e capacidade de generalização, sem esquecer as especificidades desse sistema. Essa literatura pode ser subdividida em análises sobre a composição do governo com foco na distribuição de ministérios entre os parceiros da coalizão e na composição partidária do governo, e em análises sobre a organização do governo, com foco no papel da presidência e no processo decisório.

A apresentação sistemática dessas contribuições teóricas busca contribuir para o debate sobre o Executivo de três maneiras específicas: primeiro, fundamentar o crescente debate sobre o Executivo apresentando as principais questões, argumentos e variáveis da literatura; segundo, enfatizar esse poder como uma arena de tomada de decisão e negociação que possui lógica própria; terceiro, evidenciar uma agenda ainda em aberto, especialmente no caso do presidencialismo de coalizão brasileiro.

Mariana Batista (mariana.bsilva@gmail.com) é Doutora em Ciência Política pela Universidade Federal de Pernambuco (UFPE) e Professora do Departamento de Ciência Política da mesma universidade. Vínculo institucional: Programa de Pós-Graduação em Ciência Política, UFPE, Recife, PE, Brasil.

\section{Referências}

Abranches, S., 1988. Presidencialismo de Coalizão: o dilema institucional brasileiro. Dados, 31(1), pp.5-34.

Alemán, E. \& Tsebelis, G., 2011. Political Parties and Government Coalitions in the Americas. Journal of Politics in Latin America, 3(1), pp.3-28.

Amorim Neto, O., 2006. Presidencialismo e governabilidade nas américas. Rio de Janeiro: Editora FGV.

Andweg, R., 2000. Ministers as Double Agents? The Delegation Process between Government and Ministers. European Journal of Political Research, 37(3), pp.377-395. DOI: 10.1111/1475-6765.00518

Ansolabehere, S.; Snyder, J.; Strauss, A. \& Ting, M., 2005. Voting Weights and Formateur Advantages in the Formation of Coalition Governments. American Journal of Political Science, 49(3), pp.550-563.

Austen-Smith, D. \& Banks, J., 1988. Elections, Coalitions, and Legislative Outcomes. American Political Science Review, 82(2), pp.405-422. DOI: 10.2307/1957393

Axelrod, R., 1970. Conflict of Interest. Chicago: Markham. 
Baron, D. \& Ferejohn, J., 1989. Bargaining in Legislatures. American Political Science Review, 83(4), pp.1181-1206. DOI: $10.2307 / 1961664$

Bassi, A., 2013. A Model of Endogenous Government Formation. American Journal of Political Science, 57(4), pp.777-793. DOI: 10.1111/ajps.12031

Batista, M., 2013. O poder no Executivo: uma análise do papel dos ministérios e da presidência no presidencialismo de coalizão brasileiro (1995-2010). Opinião Pública, 19(2), pp.449-473. DOI: 10.1590/S0104-62762013000200009

, 2014. Presidentialism and Coalition Governments: on the infuence of cabinet ministers in the decision-making process. In $18^{\circ}$ Annual Meeting of the International Society for New Institutional Economics. Durhan.

Bawn, K. \&AMP; Rosembluth, F., 2006. Short versus Long Coalitions: Electoral Accountability and the Size of the Public Sector. American Political Science Review, 50(2), pp.251-265. DOI: 10.1111/j.1540-5907.2006.00182.x

Bonvecchi, A., 2014. Controlar, Organizar, Gerenciar: el estudio del centro presidencial y la coordinación del Poder Ejecutivo. In 2nd International Conference on Comparative Presidential Studies and Presidentialism. Belo Horizonte.

Bonvecchi, A. \& Scartascini, C., 2011. The Presidency and the Executive Branch in Latin America: What We Know and What We Need to Know. Inter-American Development Bank Working Paper Series, Idb-wp-283.

Budge, I. \&AMP; Laver, M., 1986. Office Seeking and Policy Pursuit in Coalition Theory. Legislative Studies Quarterly, 11(4), pp.485-506. DOI: 10.2307/439930

Carmelo, M. \& Coutinho, M., 2014. La Centralidad del Centro: Rol y Relevancia de las Secretarías Presidenciales en Argentina. In Seminario sobre Centro Presidencial America Latina, Estados Unidos, España. Montevideo.

Carroll, R., 2007. The Electoral Origins of Governing Coalitions. Tese de Doutorado. San Diego: University of Califórnia.

Carroll, R. \& Cox, G., 2007. The Logic of Gamson's Law: Pre-election Coalitions and Portfolio Allocations. American Journal of Political Science, 51(2), pp. 300-313. DOI: 10.1111/j.1540-5907.2007.00252.x

2012. Shadowing Ministers: Monitoring Partners in Coalition Governments. Comparative Political Studies, 45(2), pp.220-236. DOI: 10.1177/0010414011421309

Cheibub, A.J., 2007. Presidentialism, Parliamentarism, and Democracy. Cambridge, UK: Cambridge University Press.

Dávila, M.; Lavados, O. \& Avendño, O., 2013. Los Gabinetes de la Concertación en Chile. America Latina Hoy, 64, pp.1130-2887.

De Swaan, A., 1973. Coalition Theories and Cabinet Formation. Amsterdam: Elsevier.

Downs, A., 1999. Uma teoria econômica da democracia. São Paulo: Edusp.

Edwards III, G., 1985. Estudando a Presidência. In M. Nelson, ed. A presidência e o sistema político. São Paulo: Editora Alfa Ômega.

Edwards III, G.; Kessel, J. \& Rockman, B., 1993. Researching the Presidency: Vital Questions, New Approaches. Pittsburgh: University of Pittsburgh Press.

Figueiredo, A., 2004. O Executivo nos sistemas de governo democráticos. BIB, 58, pp.7-28.

2007. Governments Coalitions in Brazilian Democracies. Brazilian Journal of Political Science, 1(2), pp.182-216.

Gamson, W., 1961. A Theory of Coalition Formation. American Sociological Review, 26(3), pp.373-382.

Hargrove, E., 1993. Presidential Personality and Leadership Style. In G. Edwards III; J. Kessel \& B. Rockman, eds. Researching the Presidency: Vital Questions, New Approaches. Pittsburgh: University of Pittsburgh Press.

Howell, W., 2003. Power without Persuasion: The Politics of Direct Presidential Action. New Jersey: Princeton University Press.

2006. Executives - The American Presidency. In S. Binder; R. Rhodes \& B. Rockman, eds. The Oxford Handbook of Political Institutions. Oxford: Oxford University Press.

Inácio, M. 2006. Entre Presidir e Coordenar: presidência e gabinetes multipartidários no Brasil. In $3^{\circ}$ Encontro Latino-Americano de Ciência Política. Campinas.

2013. Escogiendo Ministros y Formando Politicos: los partidos en gabinetes multipartidistas. América Latina Hoy, 64 , pp.41-66.

Inácio, M. \& M. Llanos, 2014. The Institutional Presidency in Latin America: A Comparative Analysis. In Annual Meeting of the American Political Science Association, Washington, D.C.

King, G., 1993. The Methodology of Presidential Research. In G. Edwards III; J. Kessel \& B. Rockman, eds. Researching the Presidency: Vital Questions, New Approaches. Pittsburgh: University of Pittsburgh Press.

Kreps, D., 1990. Game Theory and Economic Modeling. Oxford: Clarendon.

Lanzaro, J., 2013. Centro presidencial. Estudio sobre alto gobierno en Uruguay. Documento online n. 01/13. Montevideo: Instituto de Ciencia Política de la Facultad de Ciencias Sociales de la Universidad de la República.

Lameirão, C., 2011. A Casa Civil como instituição do Executivo federal. Desigualdade e Diversidade, Ed. Especial.

Laver, M., 1998. Models of Government Formation. Annual Review of Political Science, 1, pp.1-25. DOI: 10.1146/annurev.polisci.1.1.1

Laver, M. \& Hunt, B., 1992. Policy and Party Competition. New York: Routledge.

Laver, M. \& Shepsle, K., 1990. Coalitions and Cabinet Government. The American Political Science Review, 84(3), pp.873-890. DOI: $10.2307 / 1962770$

1994. Cabinet Ministers and Parliamentary Government. Cambridge, UK: Cambridge University Press.

1996. Making and Breaking Governments: Government Formation in Parliamentary Democracies. New York: Cambridge University Press.

Laver, M. \& Shofield, N., 1990. Multiparty Government: The Politics of Coalition in Europe. Oxford: Oxford University Press. 
Lewis, D., 2009. Revisiting the Administrative Presidency: Policy, Patronage, and Agency Competence. Presidential Studies Quarterly, 39(1), pp.60-73. DOI: 10.1111/j.1741-5705.2008.03658.x

Martin, L. \& Vanberg, G., 2004. Policing the Bargain: Coalition Government and Parliamentary Scrutiny. American Journal of Political Science, 48(1), pp.13-27. DOI: 10.1111/j.0092-5853.2004.00053.x , 2011. Parliaments and Coalitions: The Role of Legislative Institutions in Multiparty Governance. Oxford: Oxford University Press.

Martin, L. \& Vanberg, G. 2013. Multiparty Government, Fiscal Institutions and Public Spending. The Journal of Politics, 75(4), pp.953-967. DOI: 10.1017/S0022381613000947

Martin, L. \&AMP; Stevenson, R., 2001. Government Formation in Parliamentary Democracies. American Journal of Political Science, 45(1), pp.33-50. DOI: 10.2307/2669358

Martinez-Gallardo, C., 2010. Inside the Cabinet: The Influence of Ministers in the Policy-Making Process. In C. Scartascini; E. Stein \&AMP; M. Tommasi, eds. How Democracy Works: Political Institutions, Actors, and Arenas in Latin American Policymaking, Washington, D.C.: Inter-American Development Bank.

Mayer, K., 2001. With the Stroke of a Pen: Executive Orders and Presidential Power. Princeton: Princeton University Press.

McCarty, N. \& Meirowitz, A., 2007. Political Game Theory: An Introduction. Cambridge, UK: Cambridge University Press.

Melo, M. \& Pereira, C., 2013. Making Brazil Work: Checking the President in a Multiparty System. New York: Palgrave/Macmillan.

Méndez, J., 2007. La oficina presidencial y el liderazgo político en México y Estados Unidos: ¿Incertidumbre competitiva o certidumbre cooperativa? Foro Internacional, 47(4), pp.839-867.

Moe, T., 1982. Regulatory Performance and Presidential Administration. American Journal of Political Science, 26(2), pp.197-224. DOI: $10.2307 / 2111036$

, 1985. The Politicized Presidency. In J. Chubb \& P. Peterson, P, eds. The New Directions in American Politics. Washington, D.C.: The Bookings Institution.

1993. Presidents, Institutions and Theory. In G. Edwards III; J. Kessel \& B. Rockman, eds. Researching the Presidency: Vital Questions, New Approaches. Pittsburgh: University of Pittsburgh Press.

Morrow, J., 1994. Game Theory for Political Scientists. Princeton: Princeton University Press.

Muller, W.; Bergman, T. \& Strom, K., 2010. Coalition Theory and Cabinet Governance: An Introduction. In: W. Strom; T. Muller \& K. Bergman, eds. 2010. Cabinets and Coalition Bargaining: The Democratic Life Cycle in Wester Europe. Oxford: Oxford University Press.

Muller, W. \& Strom, K. 2000. Coalition Governments in Western Europe. Oxford: Oxford University Press.

Neustadt, R., 1961. Presidential Power: The Politics of Leadership. New York: John Wiley \& Sons.

Pereira, C.; Praça, S.; Batista, M. \& Lopes, F. 2013. Top Managers and Risk of Policy Expropriation in Multiparty Presidential Regimes. In International Workshop on Coalition Management in Multiparty Presidentialism in Comparative Perspective. Rio de Janeiro.

Persson, T.; Rolland, G. \& Tabellini, G., 2007. Electoral Rules and Government Spending in Parliamentary Democracies. International Quarterly Journal of Political Science, 2(2), pp.1-34. DOI: 10.1561/100.00006019

Praça, S.; Freitas, A. \& Hoepers, B., 2011. Political Appointments and Coalition Management in Brazil, 2007-2010. Journal of Politics in Latin America, 3(2), pp.141-172.

Rennó, L. \& Gaylord, S., 2012. Behind Closed Doors: Cabinet Authorship of Legislative Proposals in a Multiparty Presidential System. In XXII World Congress of Political Science. Madrid.

Riker, W., 1962. The Theory of Political Coalitions. New Haven: Yale University Press.

Rubinstein, A., 1982. Perfect Equilibrium in a Bargaining Model. Econometrica, 50(1), pp.97-110. DOI: 10.2307/1912531

Rudalevige, A., 2002. Managing the President's Program: Presidential Leadership and Legislative Policy Formulation. New Jersey: Princeton University Press.

Rudalevige, A. \& Lewis, D., 2005. Parsing the Politicized Presidency: Centralization and Politization as Presidential Strategies for Bureaucratic Control. In Annual Meeting of the American Political Science Association. Washington, D.C.

Siavelis, P., 2010. Formal and Informal Organization of the Executive Branch in Chile. In V Congreso Latinoamericano de Ciencia Politica. Buenos Aires.

Stepan, A., 1990. Parlamentarismo x presidencialismo no mundo moderno: revisão de um debate atual. Estudos Avançados, 4(8), pp.96-107. DOI: 10.1590/S0103-40141990000100007

Strom, K.; Muller, W. \& Bergman, T., 2010. Cabinets and Coalition Bargaining: The Democratic Life Cycle in Wester Europe. Oxford: Oxford University Press.

Thies, M., 2001. Keeping Tabs on partners: the logic of delegation in coalition governments. American Journal of Political Science, 45(3), pp.580-598. DOI: 10.2307/2669240

Vieira, M., 2014. Como o Conflito de Políticas do Gabinete Afeta a Criação de Burocracias Públicas Centralizadas na Presidência? In Encontro Anual da Associação Brasileira de Ciência Política. Brasília.

Von Neumann, J. \&AMP; Morgenstern, O., 1944. Theory of Games and Economic Behavior. New Jersey: Princeton University Press.

Warwick, P. \& Druckman, J., 2001. Portfolio Salience and Proportionality of Payoffs in Coalition Governments. British Journal of Political Science, 31(4), pp.627-649. DOI: 10.1017/S0007123401000242

Wood, R., 1988. Principals, Bureaucrats and Responsiveness in Clear Air Enforcements. American Political Science Review, 82(1), pp.213-234. DOI: 10.2307/1958066 
Wood, R. \& Waterman, D., 1991. The Dynamics of Political Control of the Bureaucracy. American Political Science Review, 85(3), pp.801-828. DOI: $10.2307 / 1963851$

\begin{abstract}
How has the literature been analyzing the Executive Branch in the different political regimes? From the basic institutional difference between presidentialism and parliamentarism we can identify two sets of major contributions to the understanding of the functioning of the Executive in democracies: the literature on the American presidency and discussions about coalition governments in European parliamentarianism. What these two sets of theories have in common is a concern with intra-executive politics. This literature is analyzed, identifying key issues, institutions, behaviors and emphasized variables. As a result we have the systematization and comparison of the main arguments about the internal workings of the Executive not only in presidentialism and parliamentarism, but also the contribution to the explanation of the specific case of coalition presidentialism.
\end{abstract}

KEYWORDS: Executive Branch; presidentialism; parliamentarism; coalitional presidentialism; cabinet.

This is an Open Access article distributed under the terms of the Creative Commons Attribution Non-Commercial License which permits unrestricted non-commercial use, distribution, and reproduction in any medium provided the original work is properly cited. 